\title{
Bionic ears: their development and future advances using neurotrophins and inherently conducting polymers
}

\author{
Graeme M Clark ${ }^{1,2}$ and Gordon Wallace ${ }^{2,3}$ \\ 'The Bionic Ear Institute, University of Melbourne, Melbourne, VIC, Australia; ${ }^{2}$ Australian Research Council Centre for \\ Nanostructured Electromaterials, Wollongong, NSW, Australia; ${ }^{3}$ The Intelligent Polymer Research Institute, University \\ of Wollongong, Wollongong, NSW, Australia
}

\begin{abstract}
The development of the multiple-channel bionic ear for hearing and speech understanding in profoundly deaf people is the result of integrating biological and physical sciences with engineering. It is the first clinically successful restoration of sensory and brain function, and brings electronic technology into a direct functional relationship with human consciousness. It presently transmits essential place and coarse temporal information for the coding of frequency, but the fine temporal and place excitation of groups of nerve fibres is inadequate for high-fidelity sound. This is required for adequate musical appreciation and hearing in noise. Research has demonstrated that nerve growth factors preserve the peripheral processes of the auditory nerves so that an electrode array placed close to these fibres could produce this fine temporal and spatial coding. The nerve growth factors can be incorporated into inherently conducting polymers that are part of the array so the peripheral processes can be preserved at the same time as they are electrically stimulated.
\end{abstract}

Keywords: bionic ear, cochlear implant, neurotrophin, inherently conducting polymers

\section{Introduction}

The interaction of polymer chemistry and biology is now likely to be important for the future development of neural prostheses; for example, advanced multiple-channel cochlear implants (bionic ears). This interaction should achieve a better interface with the auditory nervous system.

With profound deafness, the loss of function is in the inner rather than the middle ear (Figure 1), and no degree of sound amplification will restore hearing. The development of the first safe and clinically effective bionic ear required contributions from physics to biology but little from polymer chemistry (Clark 2003b).

The original research on experimental animals aimed to first see if it would be effective to electrically stimulate residual hearing nerves to reproduce the normal coding of sound frequencies. The second aim was to see if it was safe (Clark 2003b).

The coding of sound first occurs in the inner ear, or cochlea, a spiral shell-shaped structure. The sense organ of hearing (organ of Corti) lies on the basilar membrane situated across the cochlea, as illustrated in Figure 2. The membrane vibrates to sounds, and these vibrations are transduced into electrical signals by the organ of Corti.

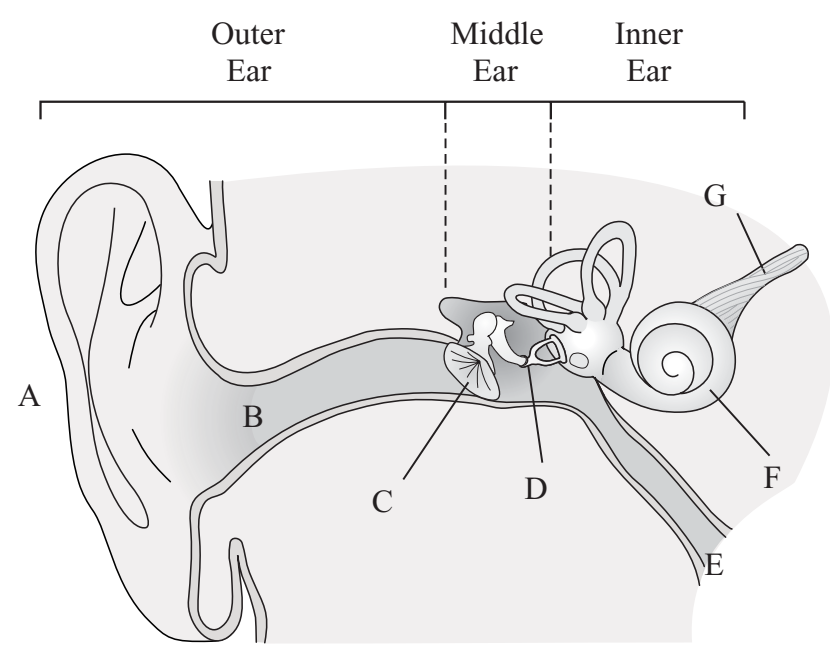

Figure I Diagram of the outer, middle and inner ears, and auditory nerve passing to the central auditory system. A-pinna, B-external auditory canal, C-ear drum, D-ossicles, E-Eustachian tube, F-inner ear, G-auditory (cochlear) nerve. Source: Clark GM. 2003. Cochlear implants: fundamentals and applications. New York: Springer-Verlag. p 58, figure 2. I. Copyright: with kind permission of Springer-Verlag.

Correspondence: Graeme M Clark, The Bionic Ear Institute, 384 Albert Street, East Melbourne, VIC 3002, Australia; tel +6I 3966775 I3; fax +6I 396677505 ; email gclark@bionicear.org 


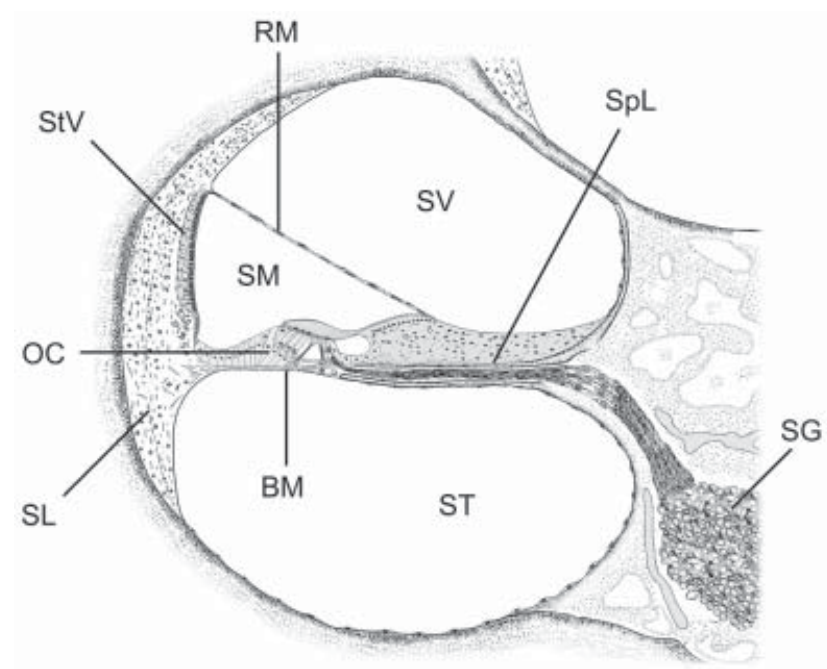

Figure 2 A cross-section of the human cochlea showing the scala tympani (ST) and the scala vestibuli (SV) separated from the scala media (SM) by the basilar membrane (BM) and the Reissner's membrane (RM), respectively. The basilar membrane is attached externally to the spiral ligament $(\mathrm{SL})$ and internally to the spiral lamina (SpL). The stria vascularis (SV) generates the endolymphatic potential in the scala media. This powers the production of cochlear microphonics in the organ of Corti (OC), and the resulting action potentials pass along the peripheral processes in the spiral lamina to the spiral ganglion cells (SG) in the spiral canal in the modiolus. Source: Clark GM. 2003. Cochlear implants: fundamentals and applications. New York: Springer-Verlag. p 74, figure 2.9. Copyright: with kind permission of Springer-Verlag.

When the organ of Corti vibrates, a shearing force develops between its hair cells and the overlying gelatinous membrane (tectorial membrane). The shearing force is transformed into patterns of electrical signals in the cochlea that then pass along the central auditory brain pathways. In sensorineural deafness, the hair cells are lost and cannot transform sound into electrical signals. Early research was carried out to see if it was possible to stimulate the hearing nerves electrically to produce similar patterns of excitation in the brain (Clark 2003b).

The coding of sound frequencies by the brain is through a combination of two mechanisms - a temporal code and a place code. The temporal code is illustrated to the left of Figure 3. The unit responses from the brainstem are on the top, and the sound waves on the bottom. Note the brain cells fire in time or phase with the sound waves. In other words, according to the temporal code there is a relation between the time intervals between nerve action potentials and the frequency of the sine wave. This relationship is weak at frequencies above approximately $1500-3000 \mathrm{~Hz}$ (Johnson 1980).

With the place code, as illustrated at the right of Figure 3, frequency is encoded through site of stimulation in the brain. The inner ear and its connections to the brain are organised spatially so that a frequency scale is preserved. High frequencies excite the basal end of the inner ear progressing a

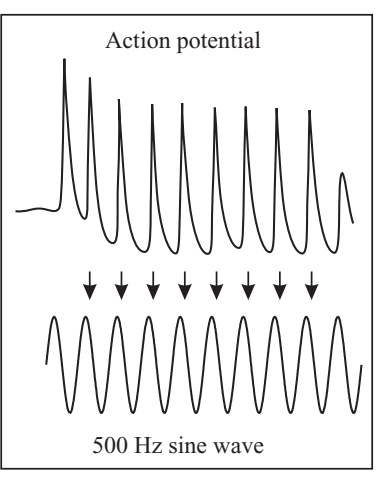

b

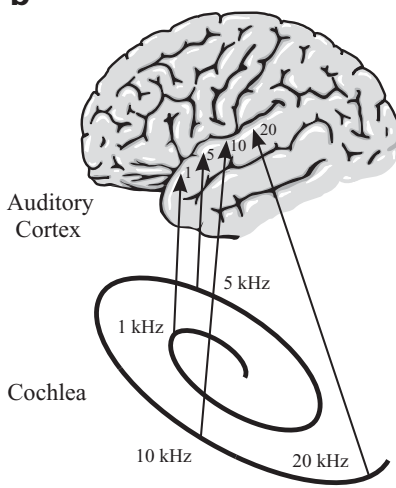

Figure 3 The temporal (a) and place (b) coding of frequency. With the temporal code (a), the brain cells (top) fire in phase with the sound wave (bottom).With the place code (b), the cochlea is connected to the higher centres in the brain (omitted for convenience) so a frequency scale is preserved. Source: Clark GM. 2000. The cochlear implant: a search for answers. Cochlear Implants Int, I:I-I7. Copyright: with kind permission of Whurr Publishers.

to low frequencies in the apical end. These regions are connected to corresponding regions of the brain so that a frequency scale is preserved.

\section{Basic biological research for a multiple-channel cochlear implant}

In the 1960s and 1970s it was not clear whether temporal coding was important for the whole range of speech frequencies from 250 to $4000 \mathrm{~Hz}$ or to what extent place coding was critical. If it had been possible to reproduce the coding of speech frequencies by rate of stimulation, ie temporal coding, only a single-channel cochlear implant would have been needed (Figure 4) and would have been simpler and cheaper to produce. On the other hand, if the higher frequencies were best coded on a place basis, and this could be reproduced with electrical stimulation, then a multiple-channel implant was required (Figure 4) but would have been more difficult to develop and more expensive.

Initial research carried out in the Physiology Department at the University of Sydney demonstrated that it was not possible to reproduce frequencies above $200-300 \mathrm{~Hz}$ using temporal coding through rate of stimulation (Clark 1969a, 1969c). This is illustrated in Figure 5. The figure shows the field potentials recorded from a number of cells in the brainstem to electrical stimulation of the auditory nerve, and how they are diminished at a rate of even $100 \mathrm{~Hz}$. This was confirmed in behavioural studies on the experimental animal. The results indicated that they could only discriminate rate of stimulation up to approximately $500 \mathrm{~Hz}$, still well short of the $4000 \mathrm{~Hz}$ needed.

Because single-channel stimulation was very limited in reproducing the temporal coding of frequency, it became 


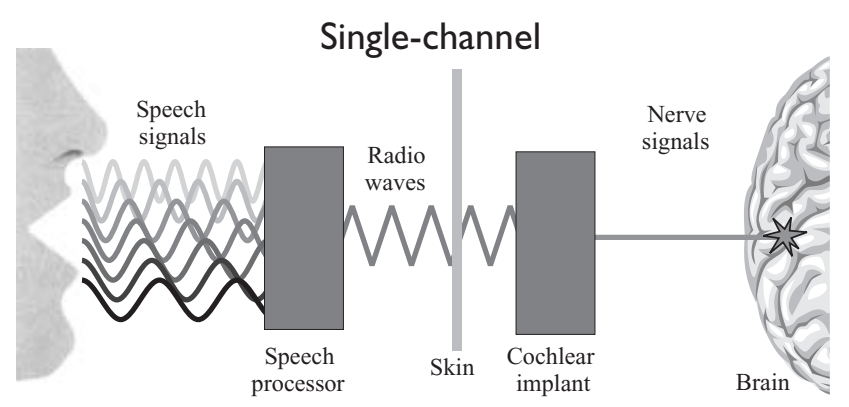

Multiple-channel

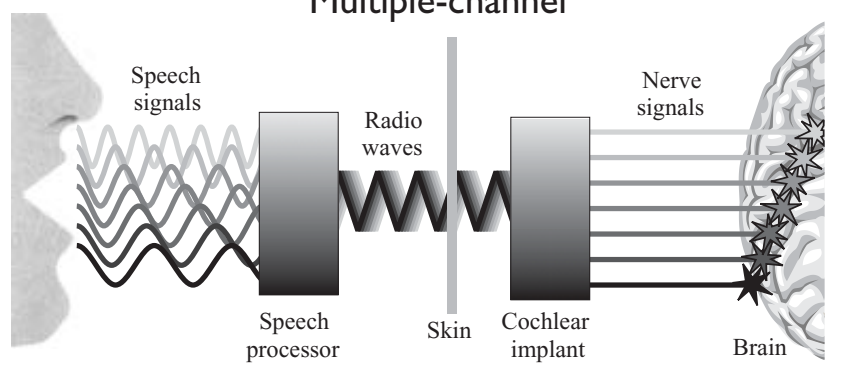

Figure 4 The concept of a single- and multiple-channel cochlear implant.

necessary to see if electrical current could be localised to discrete groups of nerve fibres to reproduce the place coding of frequency through multiple-channel stimulation. At first, this too seemed to present problems, as electrical current could short-circuit through the fluid in the inner ear and not be localised to nerve fibres. With bipolar stimulation (with current passing through two nearby electrodes) (Merzenich 1975) and common-ground stimulation (with current passing between one active electrode on the array and all the others) the current short-circuited (Black and Clark 1977); however, it was found that with monopolar stimulation (with the current flowing from an electrode sited near the auditory spiral ganglion cells to a more distant ground) the current could be localised in part (Black and Clark 1977; Busby et al 1994) (see Figure 6).

The research in the experimental animal to reproduce the temporal and place coding of frequency with electrical
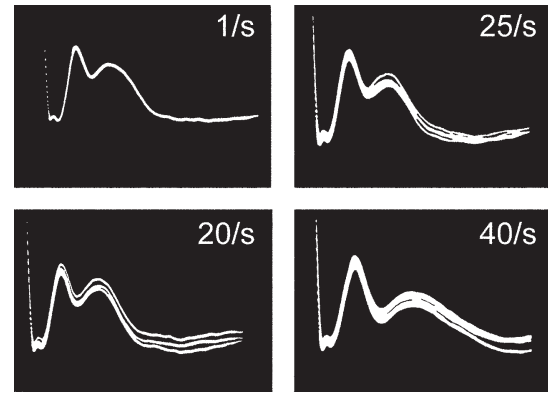

Figure 5 Field potentials for different rates of electrical stimulation (Clark 1969b).
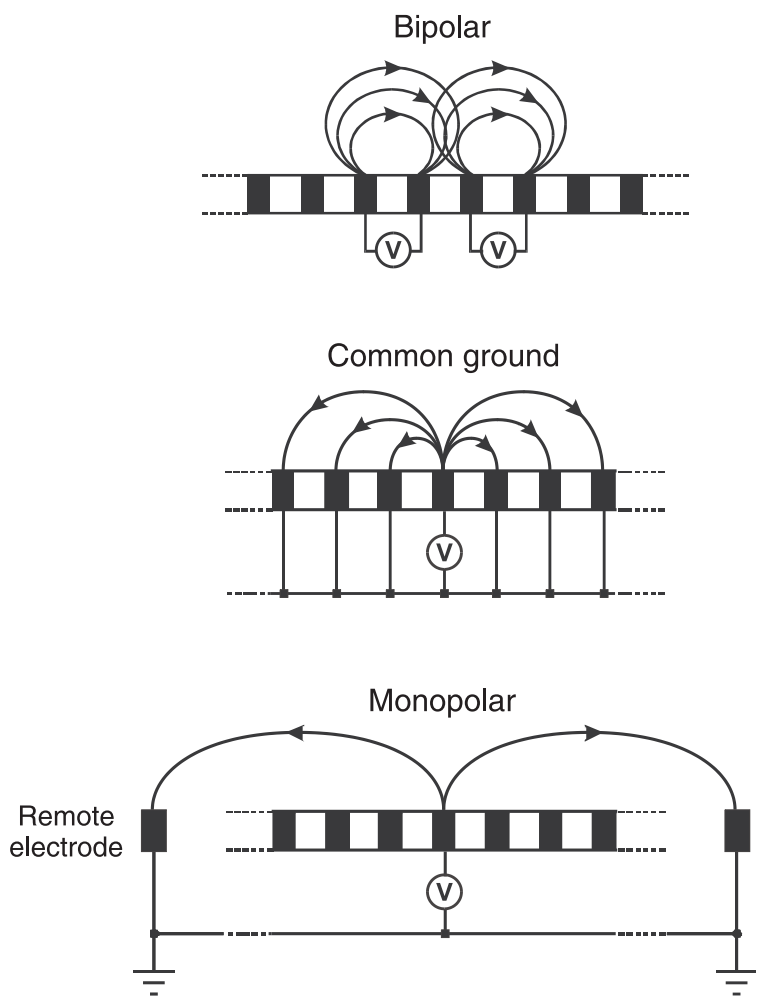

Figure 6 Bipolar, common-ground and monopolar stimulation. Source: Clark GM. 2003. Cochlear implants: fundamentals and applications. New York: SpringerVerlag. p 263, figure 5.33. Copyright: with kind permission of Springer-Verlag.

stimulation had shown that temporal and place coding of frequency could only be partially reproduced by electrical stimulation. This meant that the interface between sound and the central nervous system was like an electroneural bottleneck (Figure 7): some but not all information could be transmitted to the central nervous system.

The electroneural bottleneck meant that to maximise the speech information transmitted and coded by the brain, it would not only need multiple-channel electrical stimulation,

Sound

Electroneural Bottleneck

Auditory Pathways

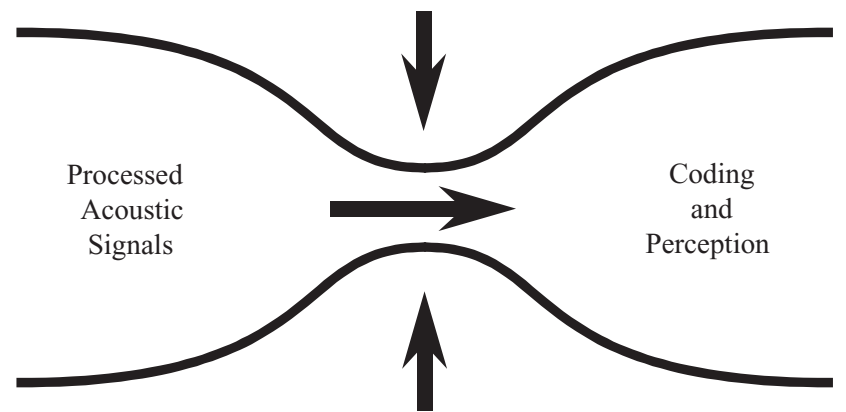

Figure 7 Electroneural bottleneck. Source: Clark GM. 2000. The cochlear implant: a search for answers. Cochlear Implants Int, I:I-17. Copyright: with kind permission of Cochlear Implants International. 
but the careful selection of the most important speech information to pass through the bottleneck.

Figure 8 shows the two concentrations of frequency energy in speech that are of the greatest importance for its intelligibility. These concentrations of energy are called formant frequencies and are shown for the syllables $/ \mathrm{ba} /$, /da/ and /ga/. It became necessary to select the second then the first formant, and finally include the energy in the third frequency region and present them as place of stimulation to transmit increasingly more information though the bottleneck for greater speech understanding. Subsequently, the selection of the six maximal outputs of a bank of 16 band-pass filters and coding their frequencies as place of stimulation produced even better results.

Thus, for effective multiple-channel stimulation of the auditory nerve fibres normally transmitting speech frequencies, the research showed it was necessary to insert multiple electrodes into the inner ear. But how could this be done safely and effectively? Most ear surgeons and biologists said it was not safe to put any foreign body inside the inner ear. The first reason for this concern was that a few patients had developed meningitis and died after a polythene strut had been used to replace the stapes for the relief of conductive or middle ear deafness. The strut barely entered the inner ear, but a middle ear infection spread around the strut to the inner ear and brain (Clark 2003a). Furthermore, surgeons and biologists said that placing electrodes in the inner ear would destroy the very nerves it was hoped to stimulate. This, however, was based on a false assumption that because traumatic removal of the stapes could destroy the organ of hearing, the same would apply to the hearing nerves.

The safety and efficacy questions that had to be addressed in the experimental animal and human temporal bone before research on patients were:
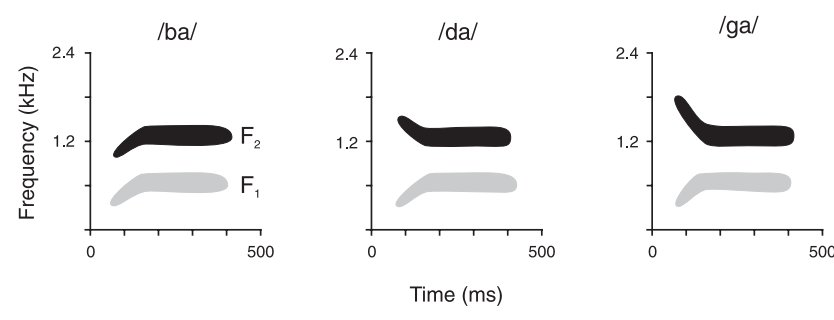

Figure 8 The first and second formants of the speech syllables $/ \mathrm{ba} /, / \mathrm{da} /$ and Iga/. Source: Clark GM. 2003. Cochlear implants: fundamentals and applications. New York: Springer-Verlag. p 392, figure 7.7. Copyright: with kind permission of Springer-Verlag.
1. Could electrodes be placed in the inner ear without injury and avoid the loss of the auditory nerves it was hoped to stimulate? The inner ear is the best location to stimulate separate groups of auditory neurons for place coding of speech frequencies. Simmons (1966) found this difficult with an array of electrodes inserted directly into the auditory nerve.

2. Could the electrodes be passed safely around the human inner ear to lie close to the nerves for speech so they could be stimulated on a place-coding basis?

3. How should the electrodes be designed to be smooth, provide safe electrical stimulus parameters, and still allow localised stimulation of separate groups of nerve fibres for place coding?

4. Could inner ear infection and meningitis be prevented? First, it was found that a smooth, free-fitting electrode array of Silastic ${ }^{\circledR}$, when gently inserted, preserved the auditory ganglion cells (Clark, Kranz et al 1975; Clark 1977). Second, it was found the electrode array could be inserted upwards around the basal turn of the tightening spiral of the inner ear and overcome friction against the outer wall to reach the region of the cochlea where the place coding of speech frequencies occurred. But the array needed to be flexible at the tip with increasing stiffness towards its basal end (Clark, Hallworth et al 1975; Clark et al 1979; Chen et al 2003) (see Figure 9).

Third, the University of Melbourne electrodes were designed to be smooth to allow the array to pass easily around the cochlea, large enough to permit safe low-charge densities, and small enough for stimulating discrete groups of nerve fibres by making them circumferential bands of

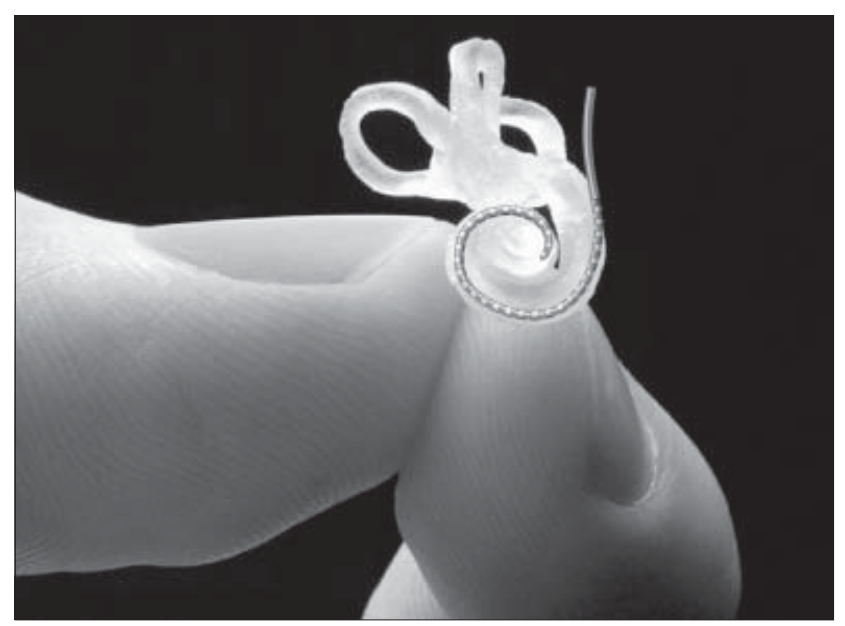

Figure 9 A mould of the human cochlea showing diagrammatically an electrode array with graded stiffness passing around the basal turn. 
platinum $0.35 \mathrm{~mm}$ in width and wrapped around the Silastic carrier with an interelectrode separation of $0.4 \mathrm{~mm}$ (Figure 10). Studies on the experimental animal then showed the charge densities required to stimulate patients (less than $32 \mu \mathrm{C} \mathrm{cm}^{-2}$ geometry) would not lead to long-term loss of the very nerves to be stimulated. Continuous stimulation 24 hours a day for 2000 hours with charge-balanced biphasic pulses had no effect on the auditory ganglion cells in the inner ear (Shepherd et al 1983).

Finally, before embarking upon clinical investigations, a number of studies on the experimental animal were undertaken to help ensure that middle ear infection would not extend around the electrode array into the inner ear and lead to meningitis (Clark, Pyman et al 1984; Clark, Shepherd et al 1984; Franz et al 1984; Cranswick et al 1987). This was a possibility because the inner ear communicates with the cerebrospinal fluid within the cranial cavity through a number of routes (Clark 2003a). The studies in the experimental animal aimed to see, in particular, if infection could be prevented from entering the inner ear by a seal around the electrode entry point.

The first infection studies showed that foreign material glued to the electrode, in particular Dacron mesh (polyethylene terephthalate), produced a foreign body reaction, and the 'dead space' in the interstices of the material provided a home for the bacteria, resulting in a severe infection that spread to the inner ear. The 'dead space' prevented the access of antibodies and reduced the phagocytic activity of the white blood cells (Zimmerli et al 1982), as well as providing a conduit for the severe infection

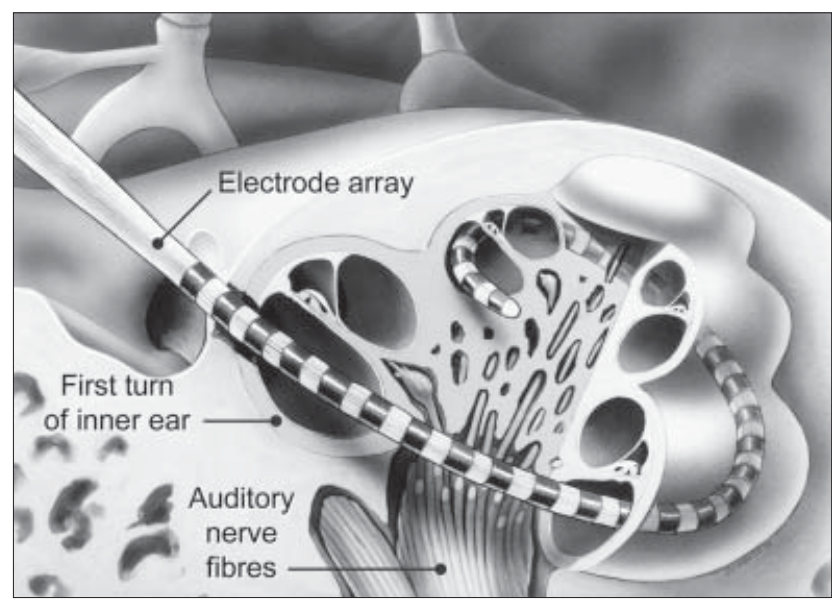

Figure 10 Banded array in the basal turns of the cochlea. Source: Cochlear Corporation. 1987. Surgical procedure manual: nucleus 22 channel cochlear implant system. Issue 5. Englewood: Cochlear Corp. Copyright: with kind permission of Cochlear Corporation.

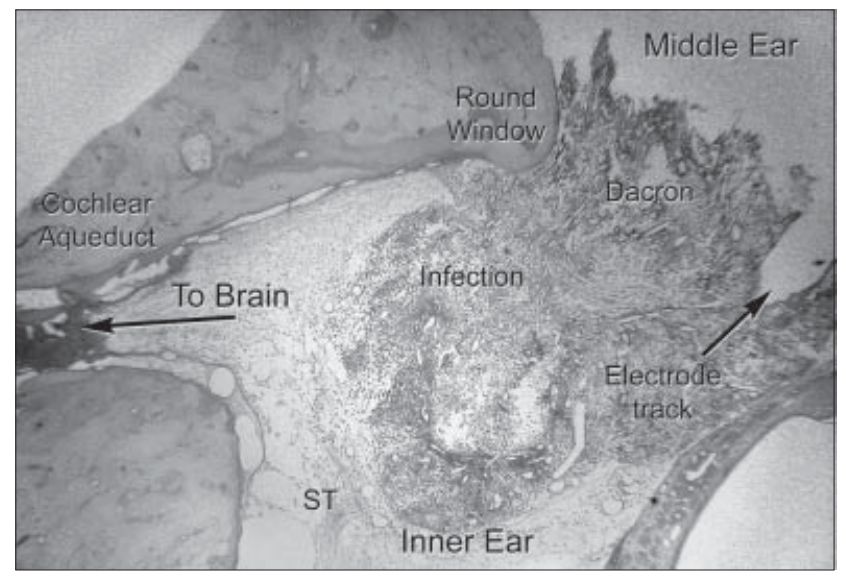

Figure I I Dacron used to seal the electrode entry point in the experimental animal and an induced middle ear infection. Notice the spread of infection to the inner ear and along the cochlear aqueduct leading towards the cerebrospinal fluid in the cranial cavity. Source: Clark GM. 2003. Cochlear implants in children: safety as well as speech and language. Int Pediatr Otorhinolaryngol, 67(Suppl I):S7-20. Copyright: with kind permission of the British Association for Paediatric Otorhinolaryngology.

to spread to the inner ear and towards the brain (Figure 11) (Clark 2003a).

Instead, natural material from the animal's body was found to be the best protection against the spread of infection to the inner ear and, in particular, fascia or fibrous tissue. Figure 12 shows that the sheath around the electrode, which formed with the assistance of a fascial graft, provided resistance against the spread of infection from the middle ear.

The fascial graft and electrode sheath prevented the entry of infection through three mechanisms. First, the lining cells of the middle ear around the electrode changed to become

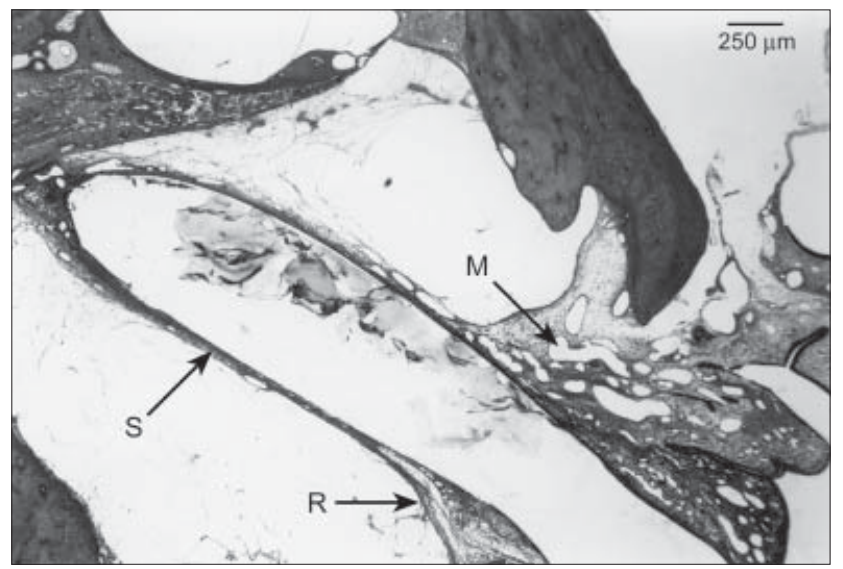

Figure 12 The prevention of middle ear infection from entering the inner ear due to a sheath around the electrode array. $S$ - sheath, $\mathrm{R}$ - thickened roundwindow membrane, $M$-mucosal folds in round-window niche. Source: Clark GM. 1990. Cochlear prostheses. Oxford: Elsevier. p 81. Copyright: with kind permission of Elsevier. 
mucus-secreting cells. The mucus has an antibacterial effect and the hairs on the cells sweep the bacteria away from the electrode entry point. Second, the electrode sheath has blood vessels connected to those in the inner ear, and, when infection commences, these vessels bring phagocytes or white cells that specialise in ingesting the bacteria to the site. Third, the infection initiates an immune response from the body, and special antibodies come from the blood stream to both the tissue within the sheath and also the space between the sheath and the foreign body. The freedom for three mechanisms to operate with a sheath around a singlecomponent array is the reason that the risk of meningitis has been shown to be similar to that of the community as a whole, except if there are risk factors such as a congenital ear where there is a free communication with the cerebrospinal fluid (Clark 2003a). In this case, there is a higher risk whether or not the ear is implanted.

The research had thus far shown the best chance for speech understanding would be through multiple-channel electrical stimulation, and the experimental animal research also demonstrated this could be done safely. The next major task was to discover how speech sounds could be coded as electrical stimuli for it to be understood.

\section{Psychophysics and speech research on deaf subjects with a multiple- channel cochlear implant}

Studies on how to encode speech with electrical stimulation could not be undertaken on the experimental animal but needed to be carried out on human 'guinea pigs'. Experimental animals understand little speech.

This appeared to present many difficulties, as speech is a complex signal, and it was not clear what information could or should be transmitted through the electroneural bottleneck, but the place coding of speech formants became an effective solution as discussed above.

Undertaking the research on patients meant developing an implantable electronic unit, rather than a plug and socket, to transmit the stimuli through the skin, as research on the experimental animal had shown a plug and socket could become infected (Clark 1987).

Engineering the implantable electronic receiverstimulator was to be very expensive, and the funds could not be raised from the peer-reviewed governmental agencies, as the world scientific opinion was that speech understanding would not be possible with electrical stimulation, as indicated by the following quotations.
'Direct stimulation of the auditory nerve fibres with resultant perception of speech is not feasible' (Lawrence 1964, p 368). 'Direct stimulation of the cochlear nerve will from time to time be discovered. There is no indication that it will ever succeed in enabling a patient to readily hear speech' (Fowler 1968, cited in Goodhill 1979, p 662).

Fortunately, funds came from public appeals through a Melbourne (Australia) television station that enabled the University of Melbourne to develop a prototype device. In preparing for the 1974 Telethon, the term 'bionic ear' was coined and used during the Nerve Deafness Appeal for funds for the electrical stimulation of the hearing nerve and then in all the associated press reports.

The bench-top model of the receiver-stimulator circuit was completed in 1976 after two years. The circuit was designed to allow flexibility in the presentation of stimulus rate and current amplitude on individual electrodes to evaluate possible speech processing strategies. A system for decoding data and power transmitted through the intact skin was incorporated.

The bench-top circuit was miniaturised through a combination of both custom-made and off-the-shelf silicon chips that were bonded to gold-plated tracks silk-screen printed onto silica wafers (Figure 13).

The University of Melbourne's prototype receiverstimulator for implantation was completed in 1978. It was hermetically sealed, and the power to operate it and the data stream were transmitted by radio waves through two separate aerials. It also had a connector (Figure 14) to enable the package to be removed (if the electronics failed), and

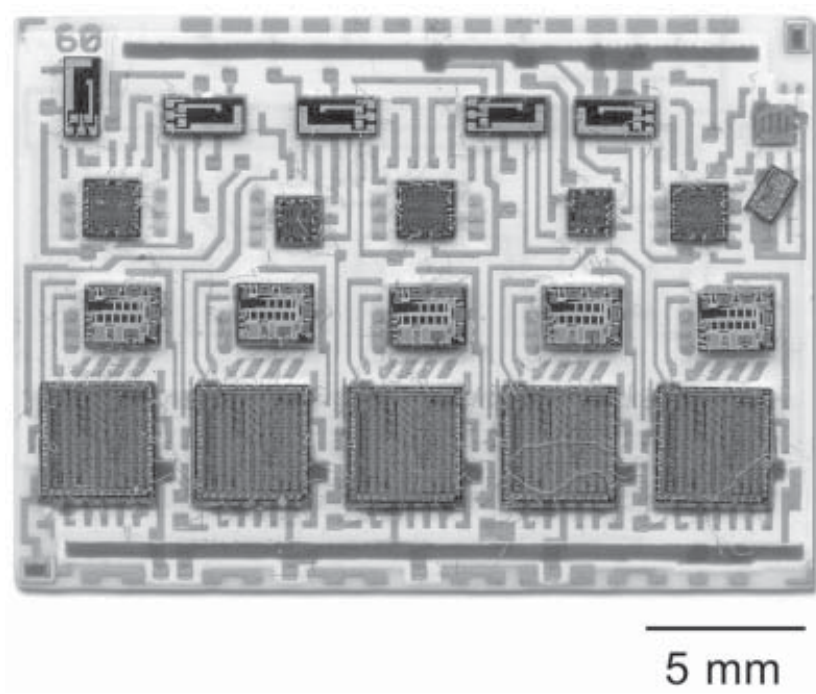

Figure I3 Integrated circuit of the University of Melbourne's prototype receiver-stimulator. 


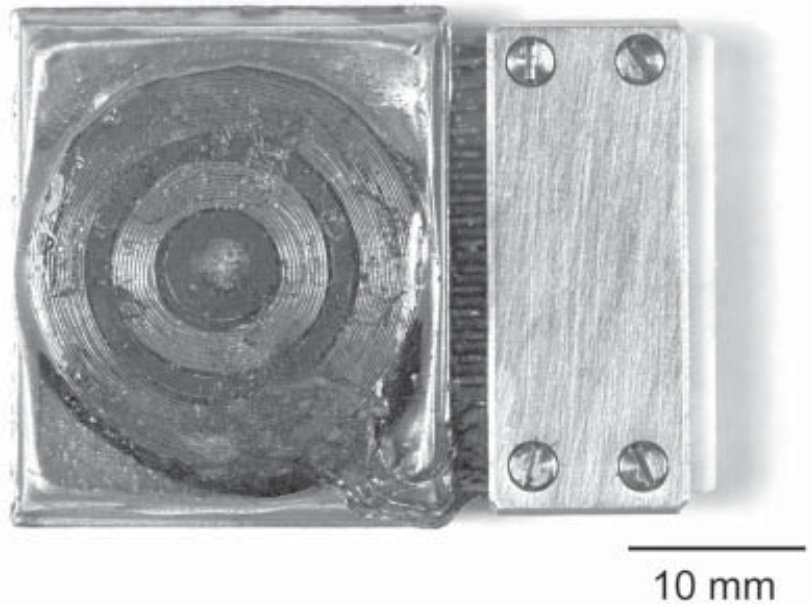

Figure 14 The University of Melbourne's receiver-stimulator with container for the electronics, two overlying coils for receiving data and power. The connector is at the right. Source: Clark GM. 1987. The University of MelbourneNucleus multi-electrode cochlear implant. In Pfaltz CR, ed. Advances in OtoRhino-Laryngology. Volume 38. Basel: Karger. Copyright: with kind permission of S Karger AG.

another inserted, without disturbing the electrodes in the cochlea.

The first patient was implanted with the prototype receiver-stimulator in Melbourne on 1 August 1978. It was undertaken in an operating theatre with a laminar flow of filtered air to ensure there was minimal risk of bacteria from the atmosphere contaminating the wound and becoming resident due to the foreign body. The patient recovered well, and, three weeks postoperatively, studies were commenced to learn what the electrical stimuli sounded like.

The first important question was: what did the patient hear for rate of stimulation? With rate of stimulation on each electrode he could distinguish pitch, but only up to

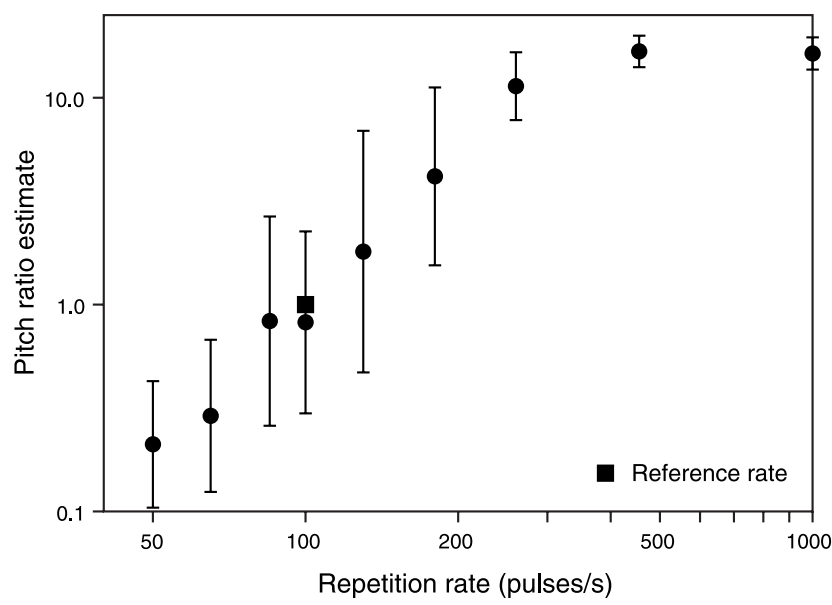

Figure I5 Rate of stimulation and pitch perception when compared with a reference rate. Source: Tong YC, Blamey PJ, Dowell RC et al. 1983.

Psychophysical studies evaluating the feasibility of a speech processing strategy for a multiple-channel cochlear implant. J Acoust Soc Am, 74:73-80. Copyright: with kind permission of the American Institute of Physics.
$300 \mathrm{~Hz}$, as shown in Figure 15 (Clark et al 1978; Tong et al 1982). This figure shows the pitch ratio versus repetition rate reached a plateau at $300 \mathrm{~Hz}$. This was predicted by the prior experimental animal findings in cats (Clark et al 1973).

For localised stimulation of each electrode with current flowing from the electrode to all the others connected together (common ground) (Figure 6), a surprising discovery was that the patient did not perceive different pitches for each electrode, but described the sensation as timbre varying from sharp (S) at the high-frequency end of the cochlea to dull (D) at the low-frequency region (Figure 16) (Tong et al 1982). Timbre is the quality of notes of the same frequency that enable a violin to be distinguished from say a horn. When the electrode timbres were compared, the timbre could be well scaled. This percept was used for place coding.

The clue to developing an effective speech processing strategy came when the patient described the sensations at each electrode not only in terms of timbre, but also as a vowel. The vowel was similar to the one with a formant frequency exciting the same area of the cochlea as the site of electrical stimulation (Figure 17).

As a result of the above findings, the following strategy was developed: (1) the second formant frequency was selected out and coded as place of stimulation; (2) the sound pressure was coded as current level and perceived as loudness; and (3) the voicing frequency was coded as pulse rate and perceived as pitch (Tong et al 1980). This multiplechannel cochlear implant (bionic ear) enabled the patient to understand running speech and became the first sensory

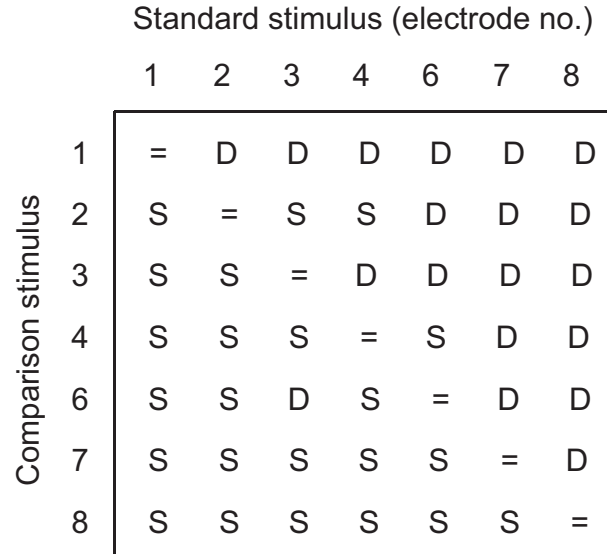

Figure 16 The scaling of pitch when the percept on a standard stimulus on one electrode was compared with the percept on each of the others. The electrodes are numbered I-8 from the low-frequency apical to high-frequency basal end of the cochlea. S-sharp and D-dull. Source: Tong YC, Clark GM, Blamey PJ et al. 1982. Psychophysical studies for two multiple-channel cochlear implant patients. J Acoust Soc Am, 7I:153-60. Copyright: with kind permission of the American Institute of Physics. 


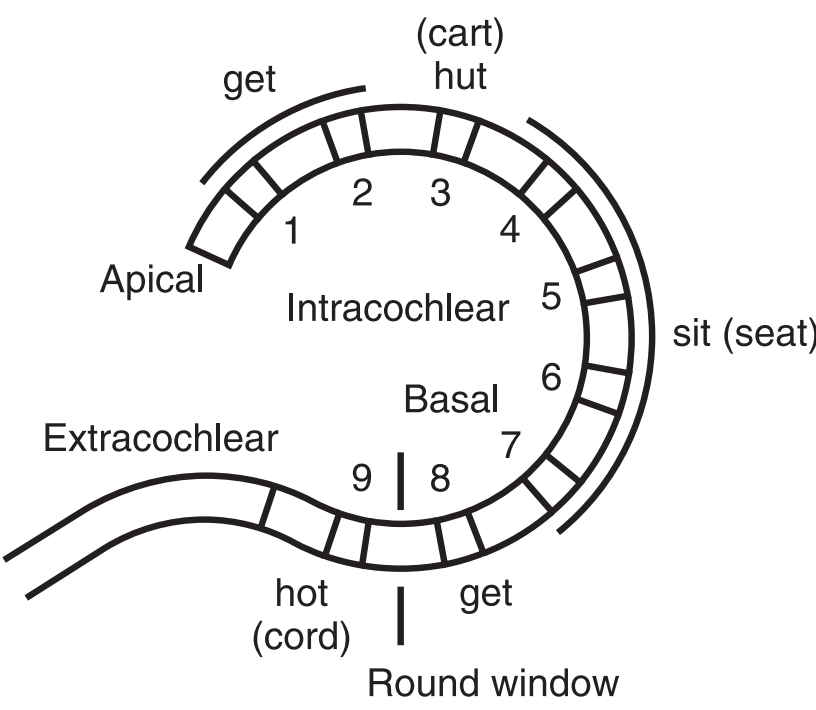

Figure 17 The vowels perceived for stimulating different sites around the cochlea. Source: Clark GM. 2003. Cochlear implants for adults and children. In Luxon L, Martini A, Furman J et al, eds. Textbook on audiological medicine: clinical aspects of hearing and balance. London: Martin Dunitz. p 417-49, figure 26.10. Copyright: with kind permission of Thomson Publishing.

and neural prosthesis to effectively and safely bring electronic technology into direct functional relationship with human consciousness. This second formant/voicing strategy was first implemented on the laboratory computer. Then it was realised as a portable unit that the patient could wear (Figure 18).

Having shown proof in principle that multiple-channel electrical stimulation of the auditory nerves could provide understanding of running speech, and that a speech processor could be produced to use in a person's daily life, it was developed industrially by Telectronics with financial support from the Commonwealth Government of Australia. The development continued through its holding company

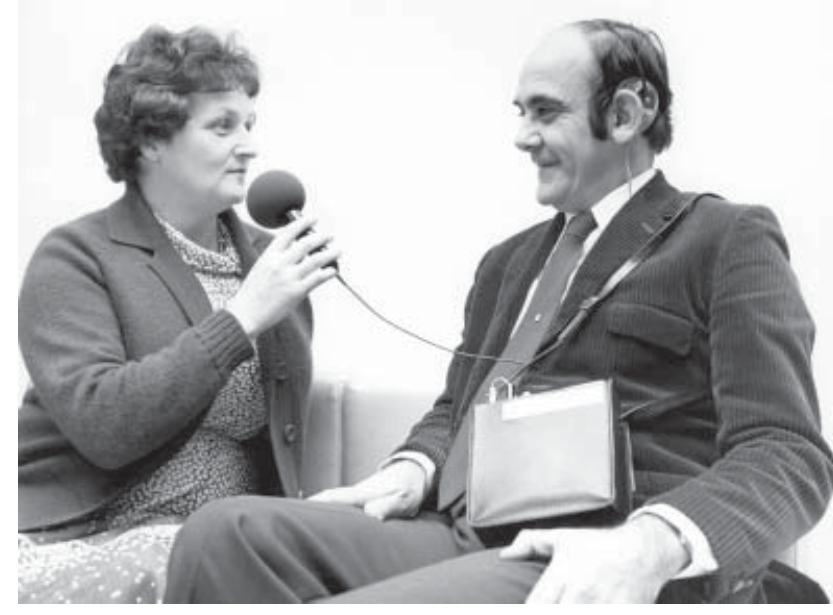

Figure 18 The first wearable speech processor being used by a patient talking with his wife. Source: Clark GM,Tong YC, Martin LF. I 98I. A multiple-channel cochlear implant. An evaluation using open-set CID sentences. Laryngoscope, 91:628-34. Copyright: with kind permission of Lippincott Williams \& Wilkins.

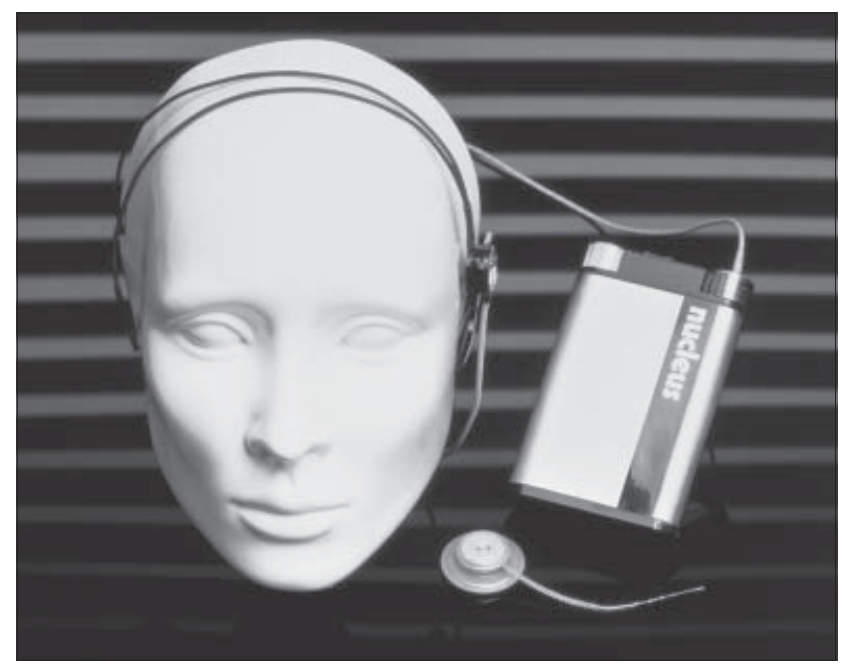

Figure 19 The first multiple-channel cochlear implant developed by Cochlear Proprietary Limited for clinical trial for the US Food and Drug Administration in 1983.

Nucleus Limited and subsidiary Cochlear Proprietary Limited. In 1985 the Cochlear Proprietary Limited multiplechannel implant (Figure 19) was the first to be approved as safe and effective in providing speech understanding for adults who had hearing before going deaf by the US Food and Drug Administration (FDA). It was also first approved in Europe in 1984 when the German government ratified it.

Psychophysical research on patients with the multiplechannel cochlear implant showed that the brain processed frequency information along three channels: spatial, coarse temporal and fine temporospatial (Figure 20). Primarily, spatial and coarse temporal information was transmitted with the cochlear implant. Nevertheless, by transmitting more frequencies on a spatial coding basis, speech perception improved. The improvements in open-set word recognition for electrical stimulation alone through the presentation of additional formants and frequency bands on a place-coding basis are shown in Figure 21. These results are for data from the University of Melbourne clinic carried out under standardised conditions.

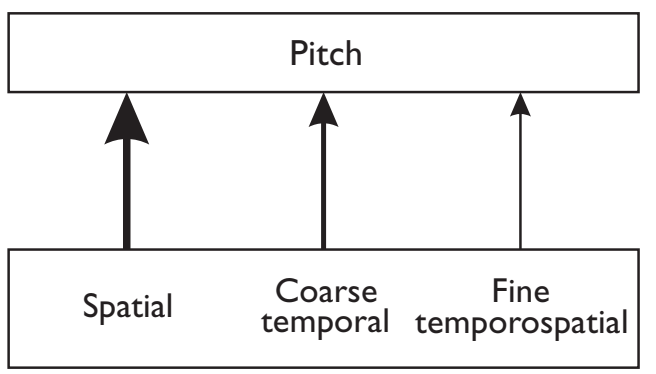

Coded information

Figure 20 A summary of the psychophysics for the processing of frequency information as shown by electrical stimulation of the auditory nerve. 


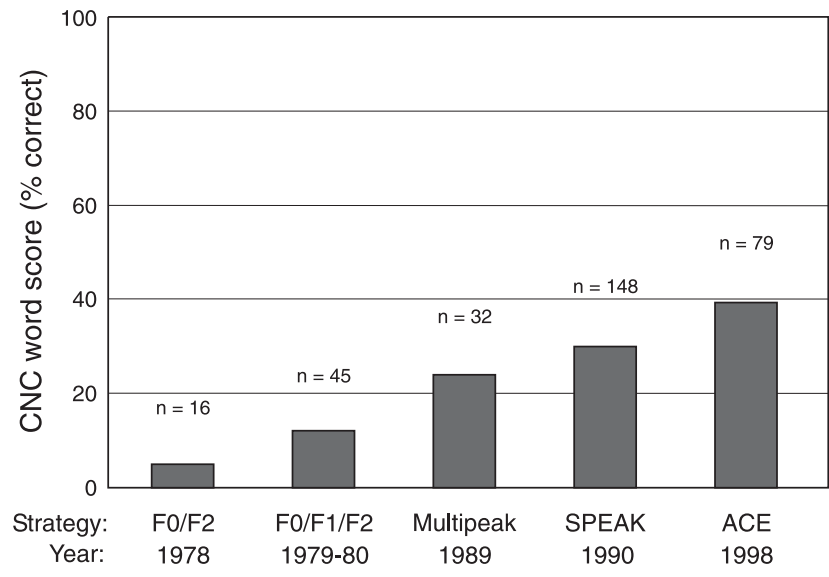

Figure 21 The improvements in open-set word scores for electrical stimulation three months after implantation with speech processing strategies presenting more formant and frequency spectral information on a place-coding basis. CNC - consonant-nucleus-consonant; $\mathrm{FO}$ - fundamental frequency; $\mathrm{FI}$ - first formant frequency; F2 - second formant frequency; Multipeak-F0, FI, F2 and high-frequency spectral bands; SPEAK - spectral maxima from 20 band-pass filters; ACE-SPEAK at high rates. These strategies were all evaluated in the University of Melbourne clinic under standardised conditions.

The multiple-channel cochlear implant was modified by Cochlear Proprietary Limited so that it could be used on children. The implant was made smaller by removing the connector, as the smooth free-fitting banded electrode array could be easily explanted and another inserted if the device failed (Clark, Pyman et al 1987). Furthermore, a rare earth magnet was placed in the centre of the transmitting and receiving aerials so that they could be easily aligned by the child, and he/she would not need a cumbersome headband as used with the previous model (Figure 22). In addition, a speech processing strategy that extracted the first as well as the second formant speech frequencies was used to present them on a place-coding basis.

It was first implanted in children in 1985 and shown to provide significant benefit (Clark, Blamey et al 1987). This

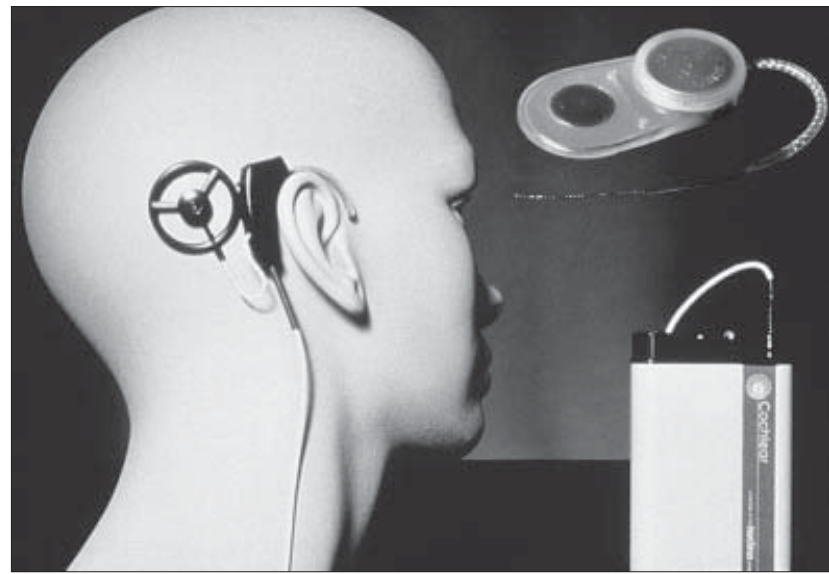

Figure 22 The Cochlear Proprietary Limited multiple-channel cochlear implant modified for use in children. led to a world trial of the implant system for the FDA. In 1990 it was the first cochlear implant to be approved as safe and effective for children by the FDA or any world regulatory body. Thus, it became the first advance in helping profoundly deaf children to communicate since sign language of the deaf was established at the Paris Deaf School 200 years ago. It has been implanted in 50000 people in more than 120 countries.

\section{The need for a new generation of bionic ears}

A new generation of bionic ears is needed, as the present multiple-channel cochlear implant, although it provides excellent speech understanding, does not give adequate high fidelity sound to appreciate the complex sounds of a symphony concert or enable people to hear in the difficult listening conditions of a cocktail party (a similar problem for hearing-aid users). The difficulty in noise is illustrated in Figure 23. As the signal and the noise approach the same intensity levels $(0 \mathrm{~dB})$, the speech scores become much worse for the implant patient compared with the person with normal hearing. This is due to the inability to transmit the fine temporospatial patterns of stimulation.

\section{Neurotrophins and auditory nerve protection and regeneration}

\section{Rationale}

In developing a new generation of bionic ears for highfidelity sound it will be necessary to obtain close contact with hundreds of smaller groups of nerve fibres rather than

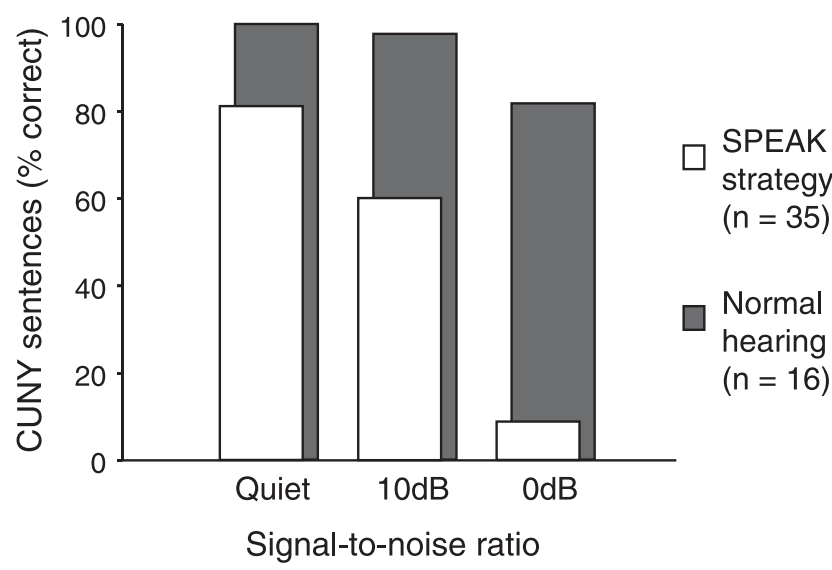

Figure 23 The speech scores for normal hearing and people with the most effective cochlear implant speech-processing strategy at different signal-to-noise ratios of multi-speaker babble. Source: Clark GM. 2003. Cochlear implants: fundamentals and applications. New York: Springer-Verlag. p 716, figure 12.2. Copyright: with kind permission of Springer-Verlag. 
the 20 larger groups as at present. This should provide sufficient fine time and spatial patterns of nerve responses for the improved coding of frequency. Currently, speech perception requires only four to six channels for optimal results with fixed-filter strategies in quiet (Wilson et al 1992); however, Blamey et al (1992) have demonstrated that with the Nucleus Multipeak and SPEAK strategies, 20 channels resulted in good performance. It is assumed that many more channels will be required for the best speech perception in noise and for musical appreciation. To ensure there will be an adequate array of nerve fibres, nerve growth factors will be needed to either prevent the peripheral processes of the auditory neurons dying back to the ganglion cells, or the ganglion cells will need to grow new peripheral processes through the bony tunnel in the spiral lamina to lie in the cochlea where they are more readily accessible. For the above reasons, not only will it be necessary to retain the present close relation between physics and biology, but also develop a major contribution from chemistry, in particular the use of functional polymers to provide a dynamic organic interface.

Furthermore, as discovered in the 35-year development of the multiple-channel cochlear implant, it is not enough to understand the biology or the chemistry of the interface, but the prosthesis will need to be adapted to the underlying physiology, anatomy and pathology of the body, and its long-term safety needs to be assured. This research on the combination of neurotrophins and polymers should not only be fundamental in developing a new generation of bionic ears, but also neural prostheses for the relief of spinal cord injury. With spinal cord injury, the tracts above the lesion, which provide motor control, and those below, giving sensation, may be helped to regenerate using a scaffold of inherently conducting polymer with neurotrophin incorporated in it.

With this research in neuroscience and nanoscience to develop more sophisticated neural prostheses, it will be necessary to address two fundamental questions: Will they be effective? Will they be safe?

Supporting evidence that the research on neurotrophins and inherently conducting polymers could be effective for an advanced bionic ear comes from the finding that a fine temporal and spatial pattern of neural responses is important for the coding of frequency (Clark 1996). Physiological research on the 'bushy' cells in the cochlear nucleus, which are important for temporal coding (Paolini et al 2001), and mathematical models of neural function (Burkitt and Clark 1999) have shown that electrical stimulation does not reproduce the fine temporal and spatial pattern of neural activity in a group of neurons that reflect the phase information produced by sound waves as they pass along the basilar membrane. A fine temporal and spatial pattern of responses is most probably necessary for high-fidelity sound (Figure 24).

If the electrodes can be placed close enough to neurons with a finer array to transmit this phase information, then the coding of high fidelity sound should be possible. The phase changes in the travelling wave are illustrated in Figure 25.

Research discussed above has shown that the higher order brain cells, in particular the 'bushy' cells in the cochlear nucleus, have the processing mechanisms to code this phase information from points 0.75 to $1.25 \mathrm{~mm}$ along the basilar membrane (Fitzgerald et al 2001). Technology has the capability to produce such an array to reproduce this coding. For there to be an ensemble of neurons for this fine degree of stimulation it will be necessary to preserve the peripheral processes of the neurons or have them regenerate. This will require incorporating functional polymers in the electrode array to control the release and/ or accessibility of nerve growth proteins.

Placing the electrode array closer to the spiral ganglion cells with an array in the scala tympani provides some improvement in the spread of current compared with that for an array lying at the periphery (Cohen et al 2001). There is, however, little evidence at present that the spread of

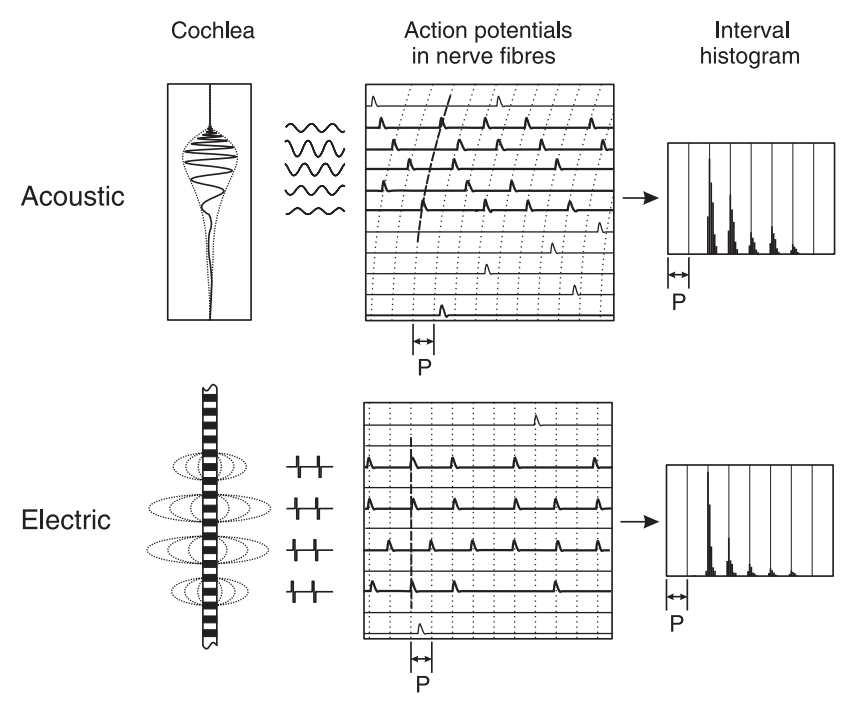

Figure 24 Interval histograms for neural responses to electrical and acoustic stimulation (right). The responses are the same for sound and electrical stimulation; however, the overall pattern in a group of neurons (centre) reflects the phase of the travelling wave as it passes along the basilar membrane in the cochlea (left). Source: Clark GM. 200I. Editorial: Cochlear implants: climbing new mountains. The Graham Fraser Memorial Lecture 2001. Cochlear Implants Int, 2:75-97. Copyright: with kind permission of Cochlear Implants International 


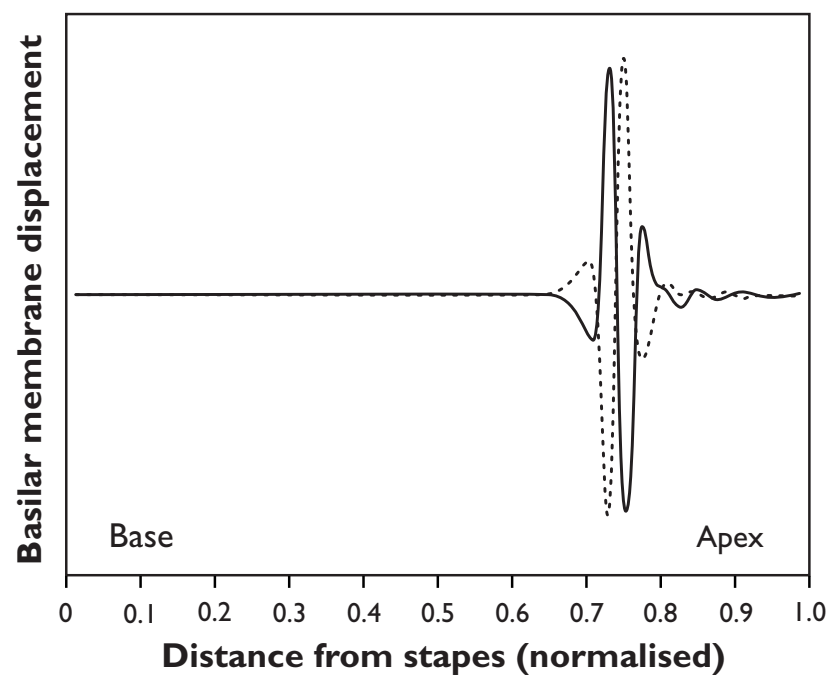

Figure 25 The basilar membrane travelling wave showing its amplitude at two points in time for a $\mathrm{I}-\mathrm{kHz}$ tone to demonstrate phase changes for a defined frequency. This acoustic model was modified by Au et al (1995) from the work of Neely and Kim (1986).

current is narrow enough to produce the improvements required for high-fidelity sound. For that reason, an array may need to rest on the peripheral processes where they emerge from the spiral lamina. This will require the development of a scala media array. For this to occur, it will be necessary to ensure that a high potassium level in the scala media does not affect neural function, and that tight junctions between cells do not limit the spread of the neurotrophin.

\section{Chemistry}

The neurotrophins are proteins and, as such, are formed from a series of amino acids (peptides) joined by covalent bonds between the amino group of one peptide to the carboxyl acid group of the adjacent one. The role of the protein depends on its shape. It has a primary structure, which is the sequence of amino acids. The secondary structure is three-dimensional due to coiling and folding from hydrogen bonding between neighbouring amino acids. The tertiary structure is the result of $\mathrm{Z}$ groups. These amino acid side chains cause variations in shape as they form hydrogen and electrostatic bonds elsewhere on the protein chain. Neurotrophins vary in size and structure. For example, neurotrophin-3 (NT-3) has a molecular weight of $27 \mathrm{kDa}$. It has a cluster of positively charged residues that bind to the receptor site on the nerve membrane. The neurotrophin can be incorporated into polymers and released to react with the nerves as discussed below.

The slow release of a neurotrophin LIF (leukaemia inhibitory factor) from calcium alginate rods to skeletal muscle can maintain its level of activity in the body over a period of months (Austin et al 1997). Thus, its incorporation into an inherently conducting polymer could be expected to prevent degradation.

\section{Mode of action}

To see how neurotrophins should be effectively used with a new generation of arrays, it was first necessary to know the best combination of nerve growth factors that prevent the death of auditory neurons and lead to their regrowth. In preventing the neurone from dying, the nerve growth factor, eg neurotrophin-3 (NT-3), blocks two receptors, TrkC and p75, on the nerve cell membrane, and this prevents the cell death cascade from being triggered by agents acting on the receptor as illustrated in Figure 26. This is summarised by Marzella and Clark (1999).

For initiating nerve regrowth, the neurotrophins also bind to one or two receptors on the nerve cell membrane; this sends a signal to the DNA for protein synthesis through a cascade of linked protein reactions as illustrated in Figure 27.

\section{In vitro selection of neurotrophin}

The effect of neurotrophins on nerve survival and growth was first studied in the test tube. Research at The Bionic Ear Institute, Victoria, Australia, and other centres has demonstrated that often a combination of neurotrophins leads to the best results, seen for example for rat pup spiral

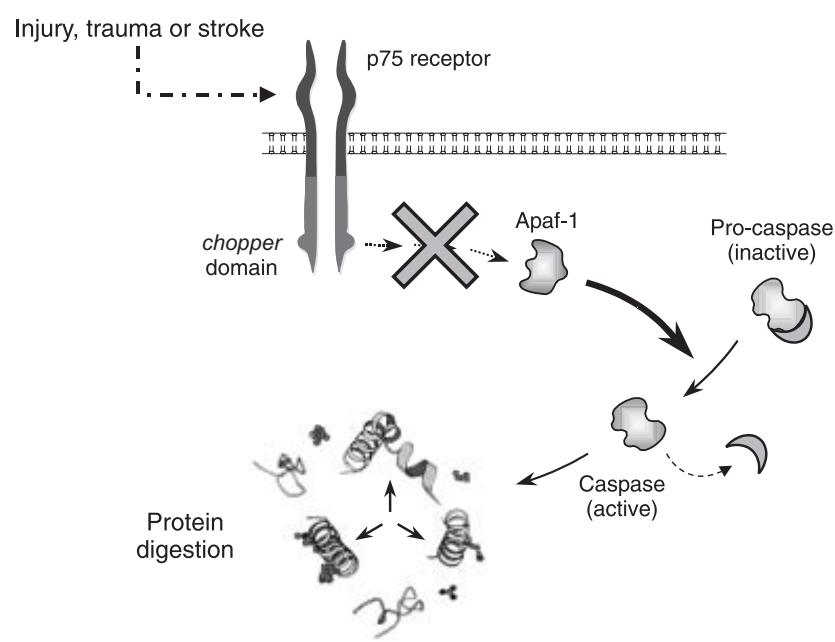

Figure 26 Diagram showing the signalling mechanisms causing cell death, and how neurotrophins block the cycle (marked with an X). Source: Clark GM. 200I. Editorial: Cochlear implants: climbing new mountains. The Graham Fraser Memorial Lecture 200I. Cochlear Implants Int, 2: 75-97. Copyright: with kind permission of Cochlear Implants International. 


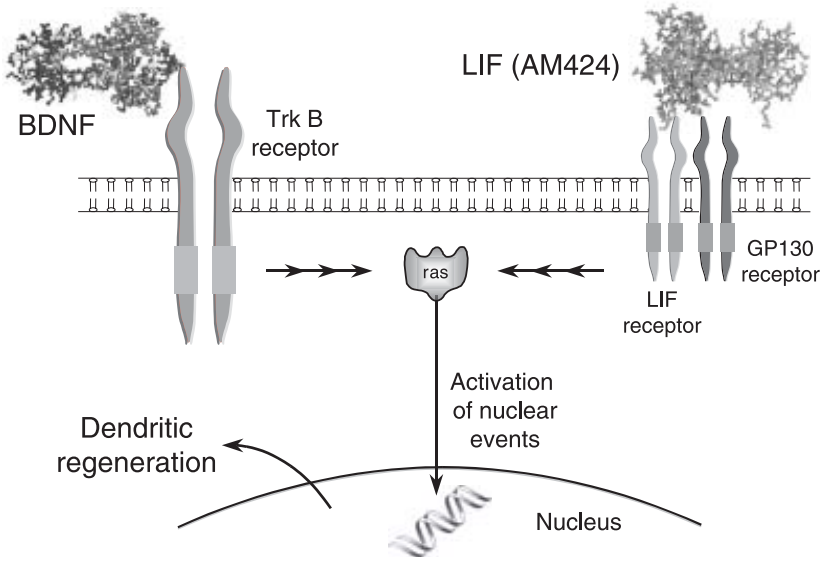

Figure 27 Neurotrophins and signalling mechanisms. BDNF - brain-derived neurotrophic factor, LIF - leukaemia inhibitory factor. Source: Clark GM. 2001 Editorial: Cochlear implants: climbing new mountains. The Graham Fraser Memorial Lecture 200I. Cochlear Implants Int, 2:75-97. Copyright: with kind permission of Cochlear Implants International.

ganglion cell survival. Transforming growth factor $\beta 3$ (TGF$\beta 3$ ) and NT-3 in combination produced greater neuron survival than either alone (Marzella et al 1997). In addition, LIF and brain-derived neurotrophic factor (BDNF) produced the greatest auditory nerve elongation, as illustrated in Figure 28 (Gillespie et al 2001).

\section{In vivo validation}

The results of the in vitro studies had to be validated in vivo. The in vitro results do not necessarily apply to the live animal, as there may be interrelated inhibitory effects from other cells and problems of tissue diffusion and uptake. The neurotrophins were infused with a micro-pump into the scala tympani of the inner ear through the round window.

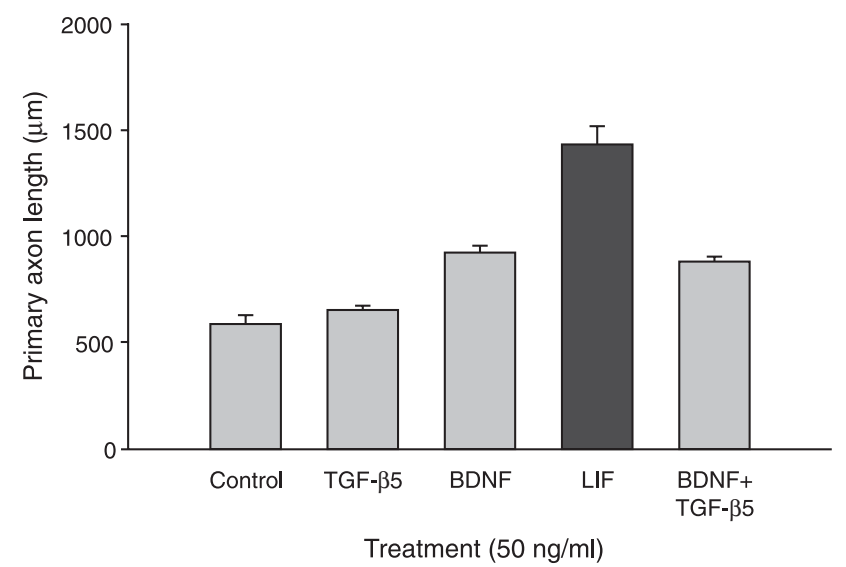

Figure 28 Trophic factors in vitro for rat pup auditory spiral ganglion cell growth. BDNF - brain-derived neurotrophic factor, LIF - leukaemia inhibitory factor, TGF- $\beta 5$ - transforming growth factor $\beta 5$. Source: Gillespie LN, Clark GM, Bartlett PF et al. 200I. LIF is more potent than BDNF in promoting neurite outgrowth of mammalian auditory neurons in vitro. Neuroreport, 12:275-9. Copyright: with kind permission of Lippincott Williams \& Wilkins.
Research on the use of neurotrophins for the restoration of hearing and cochlear implantation has been reviewed by Marzella and Clark (1999).

In one study (Gillespie et al 2003), guinea pigs were deafened by the administration of ototoxic antibiotics, leading to the loss of the hair cells as well as the spiral ganglion cells of the auditory neurons. BDNF was infused into the scala tympani of the inner ear on one side five days after the ototoxic drugs were administered, and the other side was the control. BDNF was instilled for four weeks, and the animals were sacrificed at five weeks. There was a $75 \%$ preservation of the spiral ganglion cells on the side where the neurotrophin was administered, but only $25 \%$ of ganglion cells on the control side. A section of a representative cochlea is shown in Figure 29. This result offered hope of preserving auditory neurons for cochlear implants to provide fine patterns of excitation for advanced coding strategies.

In another study, it was shown that the peripheral processes of the auditory neurons as well as the spiral ganglion cells were preserved with the infusion of both BDNF or NT-3. This was demonstrated for the myelinated section of the nerve stained with $\mathrm{OsO}_{4}$ (Wise $\mathrm{A}$, pers comm, Jun 2003). The finer, more peripheral, unmyelinated nerve fibres passing out through the habenula perforata and across the basilar membrane to the organ of hearing (Corti) were also shown to be preserved with neurotrophins after deafening, using confocal microscopy. Preservation of this network of neural processes would be necessary for finer patterns of stimulation in people who are recently deafened. On the other hand, with long-standing sensorineural deafness the majority of people have lost their peripheral processes and only have a proportion of spiral ganglion cells remaining. In 93 cochleae from profoundly deaf people,

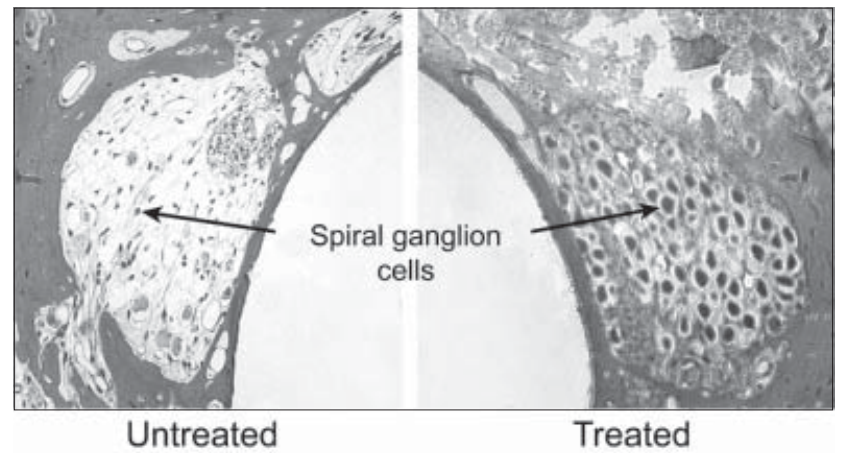

Figure 29 The guinea pig cochlea after BDNF (brain-derived neurotrophic factor) infusion. Source: Gillespie LN, Clark GM, Bartlett PF et al. 2003. BDNFinduced survival of auditory neurons in vivo: cessation of treatment leads to accelerated loss of survival effects. J Neurosci Res, 71:785-90. Copyright: with kind permission of Wiley Publishers. 
Nadol et al (1989) found the main spiral ganglion population was half the normal. Consequently, as discussed above (Wise A, pers comm, Jun 2003), the neurotrophin can also cause the regeneration of new peripheral processes that could be electrically stimulated.

Neurotrophins thus provide the auditory neurons with the trophic factors needed for survival of the spiral ganglion cells and their peripheral processes after a chemical insult and the regeneration of their peripheral processes after more long-standing deafness. But the question then was: would it be necessary to continue to administer the trophic factor, or is one presentation enough to maintain the integrity of the neuron once the hair cells have been lost?

In the next study, it was shown the neurotrophin caused cell preservation during its administration, but, after it was stopped, the nerve survival fell to a level comparable to the control untreated side (Figure 30) (Gillespie et al 2003). This indicated the need to either combine the trophic administration with electrical stimulation, or introduce adult stem cells that could continue to provide the factors.

The effect of combining electrical stimulation with the perfusion of the neurotrophin versus either neurotrophin alone or electrical stimulation alone showed that electrical stimulation (using conventional electrodes such as platinum) alone does not have any significant effect, but neurotrophin alone does. The effect is greatest when electrical stimulation is combined with neurotrophin (Figure 31) (Shepherd et al 2002). It is now necessary to know if electrical stimulation alone will maintain the nerve survival achieved after the administration of neurotrophin. This is a key question for the development of neural prostheses as it would be difficult to continue the administration of neurotrophin long term.

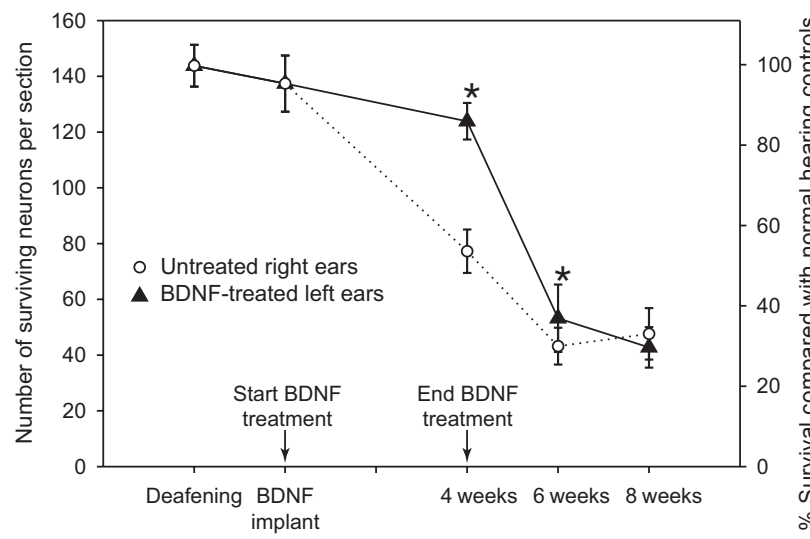

Figure 30 Neurotrophins and survival after the drug has been stopped. BDNF - brain-derived neurotrophic factor. Source: Gillespie LN, Clark GM, Bartlett PF et al. 2003. BDNF-induced survival of auditory neurons in vivo: cessation of treatment leads to accelerated loss of survival effects.J Neurosci Res, 71:785-90. Copyright: with kind permission of Wiley Publishers.

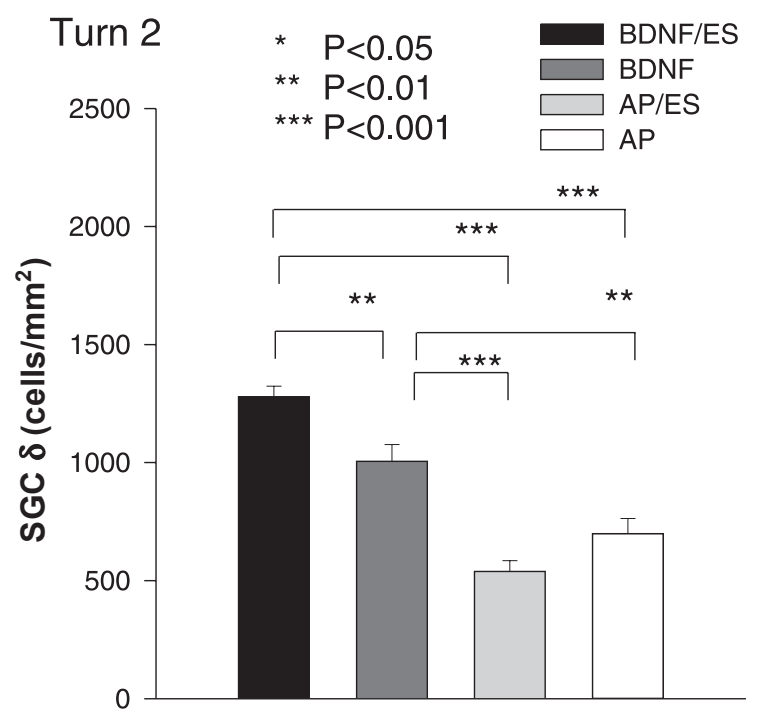

Figure 3I The effects of neurotrophins with and without electrical stimulation on spiral ganglion cell (SGC) density in the second turn of the guinea pig cochlea. Source: Shepherd et al (2002). BDNF - brain-derived neurotrophic factor, ES - electrical stimulation, AP - artificial perilymph.

\section{Transport of neurotrophin}

The next question regarding neural prostheses was: how best to transport the neurotrophin to the neuron? This required determining the amount reaching the neuron and required to activate it, other types of cells receiving the neurotrophin and the fate of the excess.

This was studied by first perfusing radio-iodine-labelled neurotrophin NT-3 into the scala tympani of deafened guinea pigs, and examining the cochleae by autoradiography and

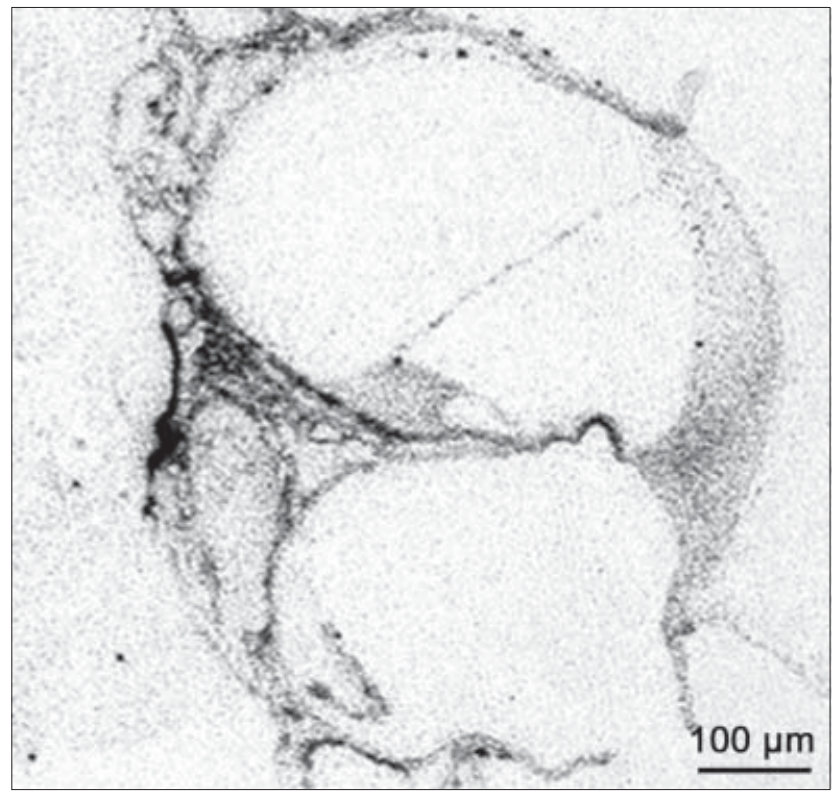

Figure 32 Radio-iodine-labelled NT-3 in the basal turn of the guinea pig cochlea after perfusion into the scala tympani. Image supplied courtesy of R Richardson, Bionic Ear Institute. 
immunohistochemistry. Results from the autoradiography study are illustrated in Figure 32. This demonstrates that labelled neurotrophin was present in the greatest concentration in the cells lining the scala tympani. There was also a strong signal in the basilar membrane, the spiral lamina (bone surrounding the peripheral process) and around the spiral ganglion cells (Richardson R, pers comm, Jun 2003). The spiral ganglion cells themselves, however, had a weaker signal. Furthermore, after 4-6 days the neurotrophin had reached all turns of the cochlea. From the radioactivity level in the spiral ganglion cell region the level of neurotrophin required for preservation of ganglion cell survival was calculated to be only tens of picograms or approximately $0.02 \%$ of the amount injected. Consequently, as the ganglion cells have the predominant number of receptors for NT-3, the perfusion is very inefficient, and an alternative method of delivery is required.

\section{The histology and anatomy for optimal electrode placement}

From the data described above, it may be desirable to place an electrode array superficial to the peripheral processes of the spiral ganglion cells where they emerge from the habenula perforata as illustrated in Figure 33.

To place the electrode in this region, it has to be anatomically and surgically feasible. This is illustrated in the histological section of the human cochlea postimplantation, where an array lies peripherally and has penetrated the basilar membrane. Thus, an array can be

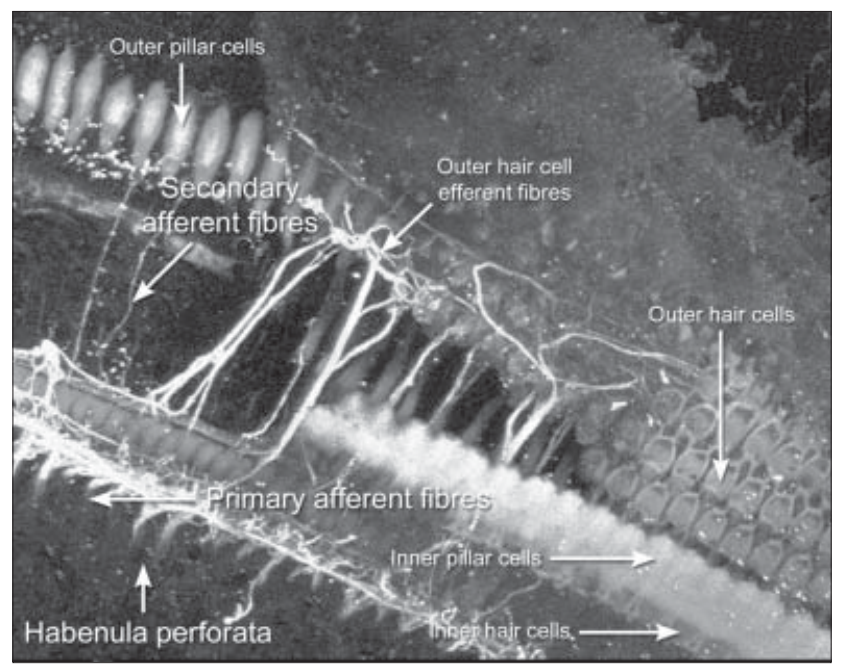

Figure 33 The peripheral processes of the spiral ganglion cells in the guinea pig cochlea shown with confocal microscopy. Image supplied courtesy of A Wise, Bionic Ear Institute.

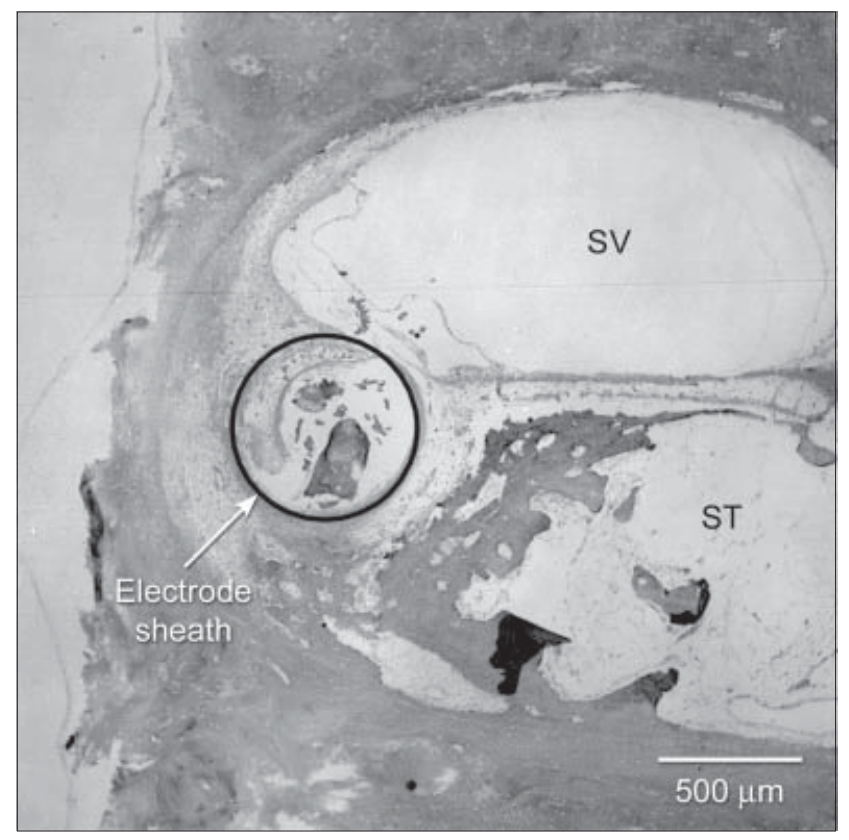

Figure 34 The anatomical placement of an electrode array in the human cochlea. SV - scala vestibuli, ST - scala tympani. Source: Clark GM. 2003. Cochlear implants: fundamentals and applications. New York: Springer-Verlag. P II I, figure 3.5. Copyright: with kind permission of Springer-Verlag.

inserted so that the combined platinum and polymer electrode lies either just beneath or on top of the neurons on the basilar membrane as shown in Figure 34.

Thus, the array could be something like the one in Figure 35. It would have platinum deposited on the array to provide electrical stimulation as well as the polymer for the release of neurotrophin. The polymer could be biodegradable and would have the neurotrophins and

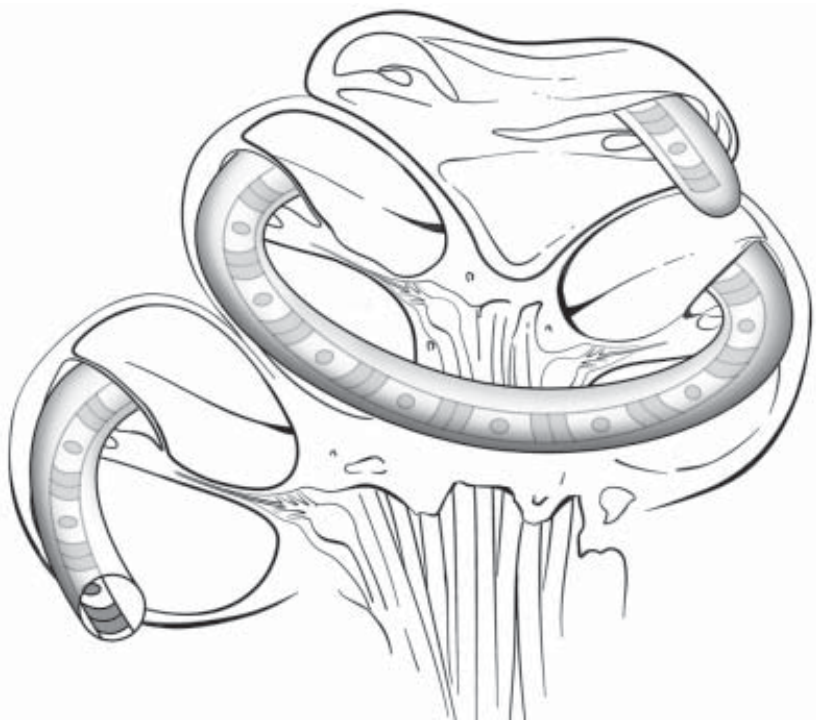

Figure 35 Surgical and bioengineering feasibility with an array containing platinum electrodes and polypyrrole to release neurotrophins. 
supporting cells to ensure continued interface with the nervous system.

\section{Inherently conducting polymers for neural prostheses}

The use of polymers as biomaterials either as prosthetic implants or scaffolds for tissue/bone regrowth has been a research area of intense activity (Dumitria 1993; Malmsten 2003). The polymer can play the role of mechanical support and/or active surface for cell attachment. In addition, the polymer may provide a reservoir for controlled release of an active molecule such as drugs or growth factors as referred to above (Illum and Davis 1987; Malmsten 2003). The ability to engineer polymer surfaces at the molecular level has enabled materials to be customised for different biological environments. It is envisioned that an electrical current would be used to release the neurotrophin from the polymer, but stimulation of the auditory neurones would occur with a thin film platinum array. Consequently, the array would be a composite one.

Just over twenty years ago, a new class of polymer materials was introduced. These are the so-called inherently conducting polymers (ICPs) discovered by MacDiarmid, Shirakawa and Heeger, examples of which are shown in Figure 36 (Shirakawa et al 1977). These new polymer materials provide an organic matrix into which biomolecules such as the neurotrophins discussed above can be readily incorporated. These new polymers being electronic conductors also provide a means for charge injection into the biological environment in which they may be used. This charge injection can be used to directly stimulate biological events or to modify the polymer-solution chemistry so that the activity of biomolecules can be regulated in situ.

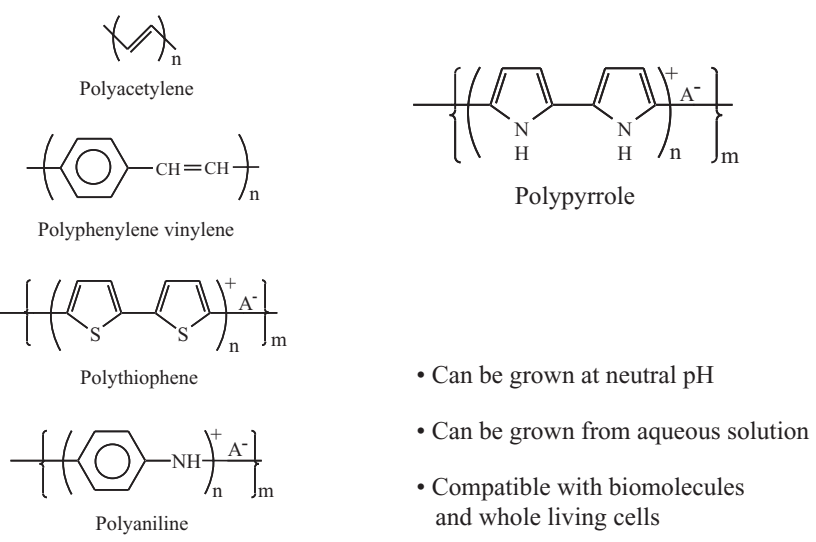

Figure 36 Examples of inherently conducting polymers. Note that polyaniline and polypyrrole are shown in 'doped' form; $\mathrm{n}$ determines charge distribution; $\mathrm{m}$ determines molecular weight.
Of the many ICPs currently available (see Skotheim et al 1998; Chandrasekhar 1999; Wallace et al 2003), the polypyrroles (PPys) have proven most effective for biological applications. The polymers can be grown at neutral $\mathrm{pH}$ from aqueous media, enabling incorporation of delicate biological molecules such as antibodies, enzymes, anticoagulants, growth factors or even whole living cells at the point of synthesis (Kane-Maguire and Wallace 2002). The properties of polypyrroles can also be switched at low potentials (see below) enabling a level of 'communication' with biological systems hitherto unavailable.

\section{Properties of polypyrroles}

Simple polypyrroles (Figure 36) are intractable, non-soluble materials capable of conducting electricity. Conductivities in the region of $400 \mathrm{Scm}^{-1}$ are routinely obtained using simple laboratory-scale preparations. Given that some metals (eg $\mathrm{Cu}$ ) have conductivities in excess of $10^{5} \mathrm{Scm}^{-1}$, this places polypyrroles in the semiconducting regime. This is important in that providing electrical stimulation to even reasonable lengths $(>5 \mathrm{~cm})$ of polypyrrole can be inefficient unless novel electrical interconnects using more conductive materials are used to ensure efficient charge injection.

In addition to being electronic conductors, polypyrroles are electroactive. They are readily oxidised/reduced resulting in significant changes in both chemical and physical properties. Critical in determining the nature of the transitions that occur upon oxidation/reduction are the characteristics of the dopant ion $\mathrm{A}^{-}$. For example, if $\mathrm{A}^{-}$is a simple small mobile anion such as $\mathrm{Cl}^{-}$, the reduction process (injecting electrons into the polymer backbone) will result in release of the anion rendering the polymer more hydrophobic, as shown in Figure 37. This hydrophobicity (inability to wet with water) arises from the fact that the polymer backbone is rendered nonpolar when the positive charge is removed by injecting electrons.

On the other hand, if the dopant anion is larger (eg dodecylsulphate) and less mobile, then electrochemical

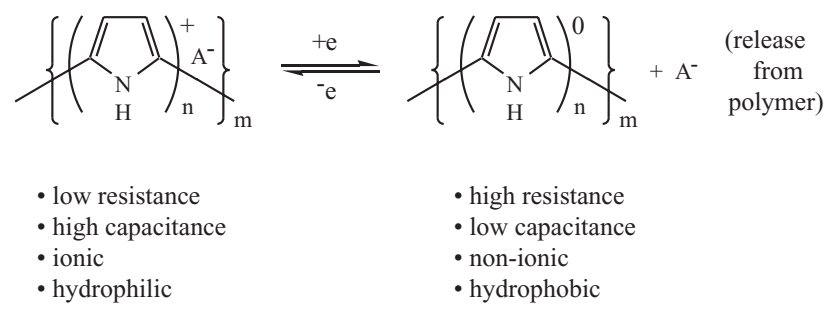

Figure 37 Electrodynamic properties of inherently conduction polymers. 
reduction of the polymer will involve incorporation of cations to balance the excess charge in the polymer. In general, as the size of the dopant increases, release from the bulk of the polymer due to reduction is more difficult (Wallace et al 2003). If the dopant has some hydrophobic character, then the reduction of the polymer to the hydrophobic state will actually increase polymer-dopant interactions mitigating against the release of $\mathrm{A}^{-}$and encouraging the incorporation of the cation.

It is possible to utilise this inherent electrodynamic character to control the binding of larger protein molecules to ICPs in situ (Smith and Knowles 1990; Khan and Wernet 1997). This is one mechanism of controlled protein release. It is, however, limited in the strength and extent of the protein binding that can be achieved. However, there are formulations utilising polyelectrolytes that function as dopants and molecular carriers (facilitating protein incorporation during growth) that do allow for triggered protein release (Hodgson et al 1996). The polyelectrolyte facilitates protein incorporation through association at the molecular level during growth. Fortuitously, the polyelectrolyte also facilitates triggered release of the protein by the fact that ICPs containing such large highly charged molecules are usually high in water content, ensuring an open porous nature conducive to transport of the larger protein molecules. These principles have been

a

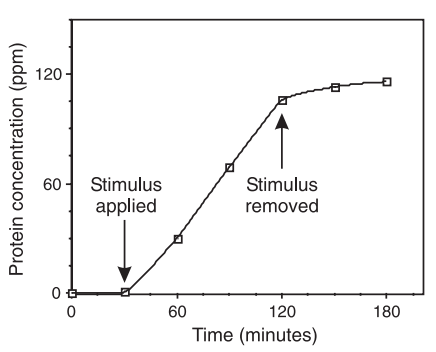

b

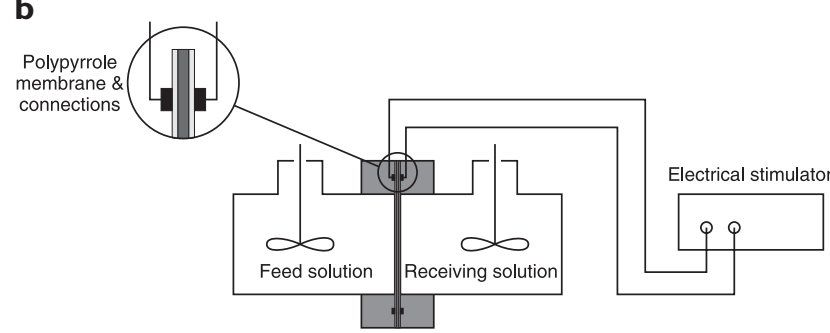

Figure 38 Controlled transport of protein (bovine serum albumin) across polypyrrole/heparin membrane: (a) concentration of protein in receiving solution; (b) schematic of membrane transport experiment. Electrical stimulation is applied at $30 \mathrm{~min}$ and removed at $120 \mathrm{~min}$, showing that protein is only transported across the polypyrrole membrane from the feed solution to the receiving solution when electrical stimulation is applied (adapted from Zhou et al 1997). demonstrated in the construction of ICP membranes that exhibit electrochemically controlled binding/transport of proteins (Zhou et al 1997) (Figure 38).

The use of an appropriate electrical stimulus enables proteins to be 'pumped' from the feed reservoir to the receiving solution. Specific molecular interactions (eg entrapment/release of thrombin) can be induced by using a polyelectrolyte (heparin) with known molecular interaction capabilities (Zhou et al 1999). Polyelectrolytes such as heparin also possess charge density characteristics that make them easily integrated into the ICP during synthesis (see below). Control of highly specific molecular interactions (antibody-antigen) can be achieved when the antibody is incorporated as the dopant anion (Figure 39) in the inherently conducting polymer (Sadik and Wallace 1993; Barnett et al 1994; Petit et al 2001) and electrical stimulation is used to control the antibody-antigen interaction.

This ability to control protein-inherently conducting (bio)polymer interactions at the molecular level through the use of electrical stimulation is not yet fully understood. However the control of a wide range of biomolecular interactions on ICP surfaces has been demonstrated on numerous occasions in a number of laboratories, and this presents an important opportunity for integration and release of the neurotrophins required for advanced cochlear implants.

\section{Integration of biomolecules into ICPS}

Appropriate binding of biomolecules and for our specific purpose neurotrophins should ideally be initiated at the point of polymer assembly. The biomolecule-ICP molecular

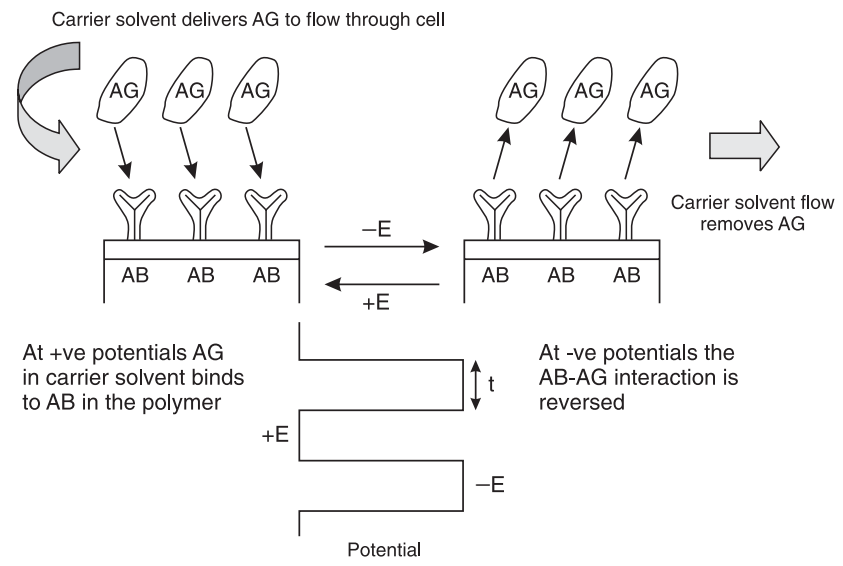

Figure 39 Controlled antibody $(A B)$-antigen (AG) interactions on inherently conducting polymers. At an appropriate positive potential (+E) AB-AG interactions are encouraged, while at other potentials $(-E)$ they are discouraged. If the potential is pulsed between these limits at an appropriate frequency $(\mathrm{I} / \mathrm{t})$ a reversible immunosensing surface to detect AG is produced. 
interactions should be strong enough for efficient incorporation but be reversible so as to be sensitive to electrical stimulation.

A number of biological entities have been incorporated as the dopant anion $\left(\mathrm{A}^{-}\right)$during synthesis (Figure 40). It has often been found that the use of a smaller (more mobile) co-dopant results in more conductive electroactive films that are still biologically active (Adeloju et al 1996, 1997). The use of polyelectrolyte co-dopants has also proven useful for incorporating proteins (Hodgson et al 1994) and even whole living cells (Campbell et al 1999). Once again the use of the polyelectrolyte not only improves the electronic and electrochemical properties of the polymer but also provides a polymeric environment (high water content) more compatible with the cells to be maintained.

In some cases, when charge density on the biological dopant molecule is sufficient (eg heparin), then no co-dopant is required. Another interesting example in this regard is the direct incorporation of DNA as the dopant molecule. The UV-visible spectra (absorption at higher wavelengths) indicates formation of a conducting material, and the cyclic voltammetry indicates discrete electrochemical switching processes (Figure 41). These properties have been used to advantage in the development of a switchable membrane system based on PPy-DNA (Misoska et al 2001), as depicted in Figure 38. Electrical stimulation has been shown to initiate transport of simple cations (eg $\mathrm{K}^{+}, \mathrm{Na}^{+}$) across the PPyDNA membranes.

As an alternative to entrapment, covalent attachment of biomolecules to ICPs is possible. For example, Umana and co-workers have attached enzymes to a PPy backbone (Figure 42a) using the well known carbodiimide chemistry (Yon-Hin et al 1993), and in other work the introduction of<smiles></smiles>

$\mathrm{H}$

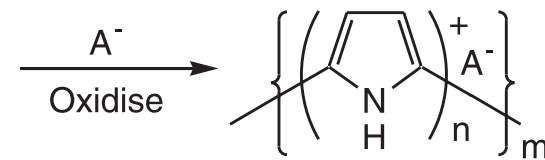

- DNA

- heparin

Biological entities incorporated during synthesis:

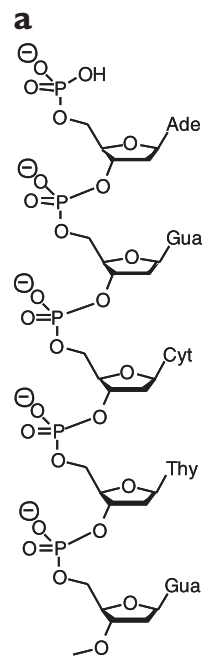

b

UV-visible spectrum indicates conducting material

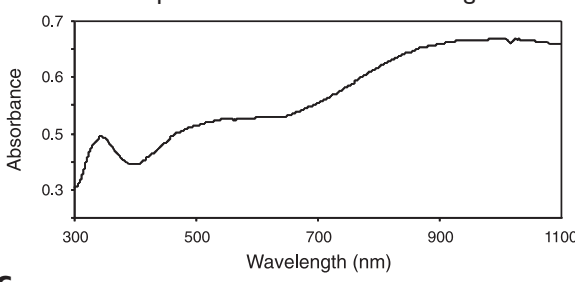

Cyclic voltammetry indicates electroactive material

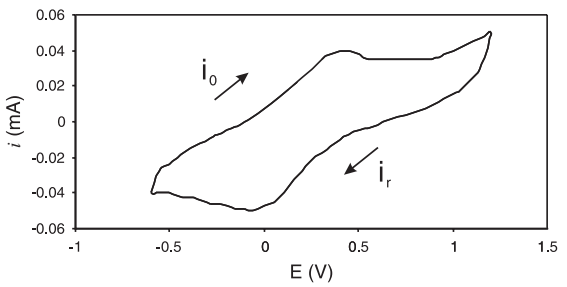

Figure 4I Polypyrrole-DNA biocomposite. (a) A single strand of DNA with molecular weight $>106 \mathrm{kDa}$. The high charge density due to the phosphate groups $\left(\mathrm{PO}_{4}\right)$ means that it can act as an efficient dopant $\left(\mathrm{A}^{-}\right)$in polypyrrole. (b) Absorbance at high wavelengths indicates smaller electronic band-gap, ie better electric conduction. Despite the dopant being a complex/large biomolecule, good conductivity and switching characteristics are obtained. (c) Current flow $i_{0}$ shows switch from neutral to oxidised form of polymer (see Figure 37). Current flow $i_{r}$ shows switch from oxidised to neutral form of polymer.

facile leaving groups (Figure 42b) has been used to produce highly bioactive surfaces with antibodies to listeria attached (Minett et al 2002).

While this approach results in a more highly bioactive surface area while using less antibody, the biological moiety is removed from intimate contact with the polymer. This mitigates against effective electrical communication either in terms of signal transduction as $\mathrm{AB}-\mathrm{AG}$ interactions occur (Minett et al 2003) or in the electrical control of AB-AG interactions. Furthermore, covalent attachment will not enable electrically stimulated release of the biomolecules to be easily achieved.

\section{Cellular communications}

Wong et al (1994) showed that the adsorption of extracellular matrix molecules, namely fibronectin (Fn), is a critical step in facilitating cell attachment to conducting polymers. They demonstrated that when aortic endothelial cells were cultured on oxidised PPy coated with Fn, cells spread normally and synthesised DNA as expected. It was also shown that when the polymer was reduced electrochemically (Figure 37), cell extension and DNA synthesis were inhibited, but cells remained viable. In other studies (Garner, Hodgson et al 1999), it was shown that vitronectin was required for adhesion of endothelial cells to heparincontaining PPys.

Figure 40 Examples of bio-entities entrapped (for a review, see Wallace and Kane-Maguire 2002). 
a

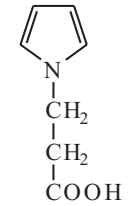

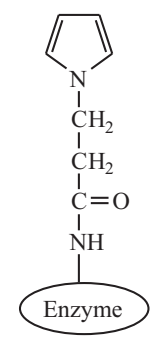

DEC $\equiv$ 1-[3-dimethylamine propyl]-3-ethyl carbodiimide hydrochloride

b

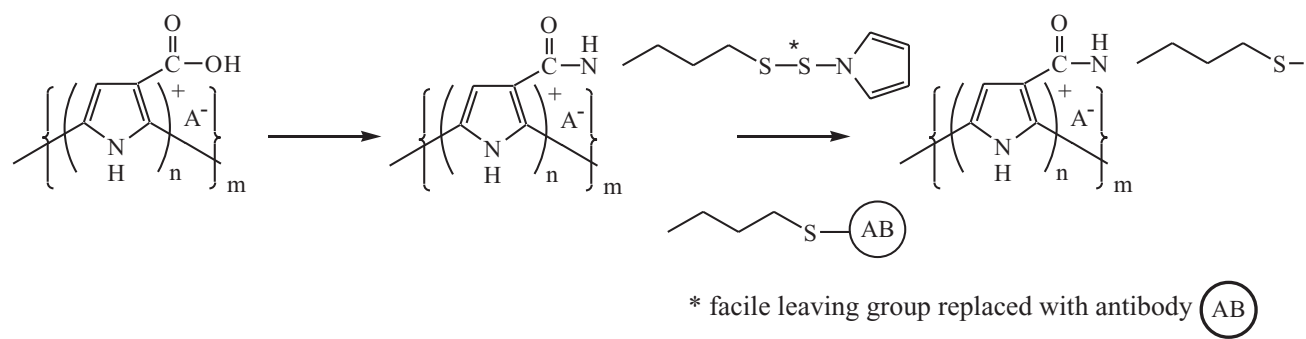

Figure 42 (a) Example of covalent attachment of enzymes to ICPs (inherently conductin polymers). (b) Example of covalent attachment of antibodies to ICPs.

In studies using polystyrene sulphonate as dopant in PPy (Kotwal and Schmidt 2001), the use of electrical stimulation was shown to enhance Fn adsorption on the polymer if it was stimulated immediately upon exposure to the proteincontaining solution. Subsequent adhesion of nerve cells to the substrate and neurite outgrowth were then improved. If the electrical stimulation was delayed (applied after a twohour period of exposure) to the Fn-containing solution, no increase in protein adsorption was observed.

The adhesion of PC-12 nerve cells to PPys containing polyelectrolytes as dopants has also been demonstrated (Hodgson et al 1994). The incorporation of nerve growth factor and the electrically controlled release of this to trigger cell growth and differentiation was also demonstrated (Hodgson et al 1996). Schimdt et al (1997) also utilised PPy platforms for PC-12 cell adhesion and proliferation. In vitro studies revealed that neurite extensions from PC-12 cells were more pronounced than on tissue culture polystyrene and that application of an electrical stimulus resulted in a significant increase in neurite length. In other studies using PC-12 cells (Shastri et al 1996), it was shown that the medium nerve outgrowth was $18.1 \mu \mathrm{m}$ with electrical stimuli applied and $9.5 \mu \mathrm{m}$ for controls. Biologically derived polyelectrolytes (heparin) have also been included as dopants in ICPs used as platforms for cell growth (Garner, Georgevich et al 1999). The advantage of such dopants is that they not only result in cellular-compatible electronic hydrogels but also bring additional biofunctionality to the
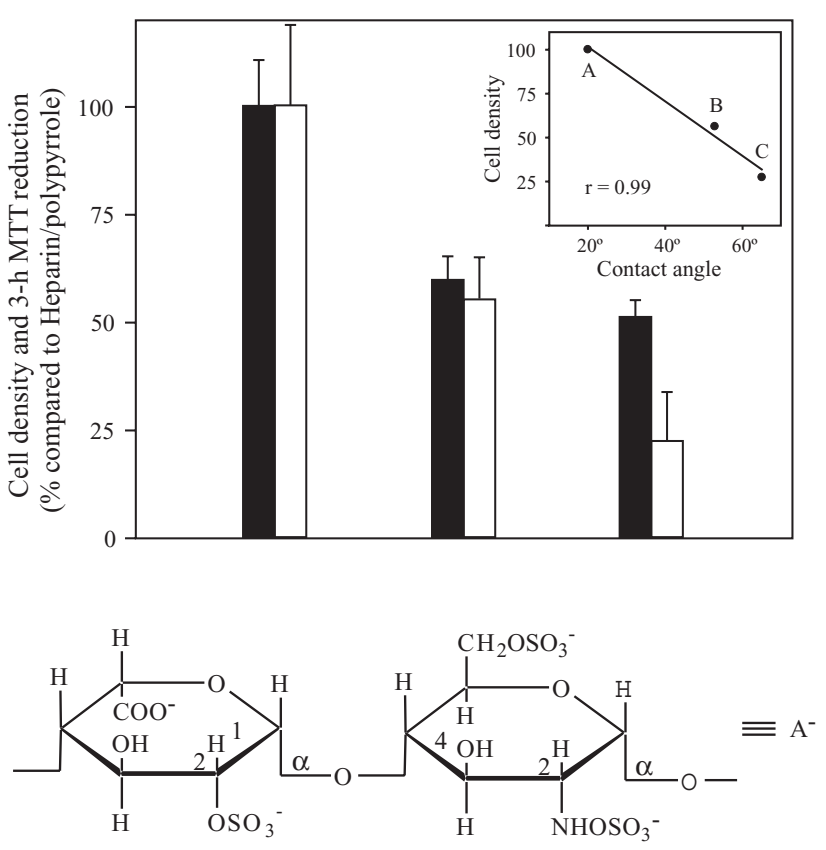

Heparin

Figure 43 Biomolecules in inherently conducting polymers enhance cell attachment (adapted from Garner, Hodgson et al 1999). Attachment of HUVEC (human umbilical vein endothelial cells) to polypyrrole composites or gold-effect of surface hydrophobicity. HUVEC were seeded at an initial density of approximately $3 \times 105$ cells per sample. The number of cells present (white bars) or the amount of MTT (methyl thiazol tetrazolium) reduced in a 3-h period (black bars) was then assessed after $90 \mathrm{~min}$. Values are standardised to the heparin-polypyrrole that was assigned a value of $100 \%$. The inset shows the correlation of the cell density versus the hydrophobicity of the samples, where $\mathrm{A}, \mathrm{B}$ and $\mathrm{C}$ are heparin-polypyrrole, $\mathrm{NaNO}_{3}$-polypyrrole and gold, respectively. Data are means and SEM (standard error of the mean) (where indicated by error bars) of two experiments each performed in duplicate. 
platform. For example, heparin is a powerful anticoagulant and is a component of the extracellular matrix of blood vessels promoting endothelial cell growth. The effect of the dopant on cell densities observed during growth were obvious (Figure 43). Chen et al (2000) also carried out in vivo studies using PPy tubes to facilitate regrowth of a severed (14-mm gap) sciatic nerve in rats.

Protocols to enable covalent attachment of polypeptides to PPy backbones have been developed (De Giglio et al 1999). These techniques were used to attach the polypeptide Cys-Gly-(Ary-Gly-Asp)-Ser-Pro-Lys to PPys coated on titanium or platinum. This polypeptide (RGD) contains the cell adhesive region of Fn. Increase in osteoblast cell adhesion of the order of $200 \%$ compared with nonpolymercoated titanium was observed (De Giglio et al 2000).

The nonapeptide (CDPGYIGSR) has also been incorporated into PPy during electrodeposition (Cui et al 2001). This laminin fragment has been shown to mediate in cell attachment and to promote neurite outgrowth. Neuroblastoma cells grew preferentially on the PPypolypeptide materials that had been coated to conventional electrode surfaces.

\section{Summary}

Inherently conducting polymers, in particular PPy, provide an organic environment capable of efficient charge transfer that is compatible with biological systems. The incorporation of enzymes, antibodies and even whole living cells during polymerisation, while retaining the molecular biological function, verifies the high degree of compatibility. Further evidence is provided by the ability to culture mammalian cells on polypyrrole surfaces. The exciting possibilities of controlling cell adhesion, proliferation and the direction of neurite outgrowth have been demonstrated.

The determination of the levels of bioactive molecule loading required, and the rate at which these should be released or activated, are issues yet to be resolved. The mechanisms underpinning such control are yet to be fully elucidated, and once fully understood these materials should provide a sound basis for the design of new biomaterials based on ICPs. In parallel, the rapid advances in ICP processing and device fabrication are particularly pertinent to the field of bionics. The ability to generate ICPs in aqueous solution (Englebienne and Weiland 1996) or as aqueous dispersions (Barisci et al 1999) that can be used to fabricate structures of different sizes, shape and configurations is important for the biomaterials engineer.
Such solutions and dispersions can then be used to create patterned 2-dimensional surfaces using traditional methods such as ink-jet printing, or to create 3-dimensional (3D) structures using electrospinning techniques. The development of protocols that result in ordered structures at the nanodomain will also impact on the biomaterials field (Boeckl et al 1998), nanotopography having already been shown to have a dramatic effect on fibroblast response (Dalby et al 2002). Strategies to enable synthesis of nanocomponents of controlled dimensions, as well as the assembly of nanodimensional structures, are being developed at a rapid rate (Innis and Wallace 2002). It has already been shown that control of the structure of ICPs at the nanodomain can have a dramatic effect on increasing the conductivity and improving the rate of switching - both properties important to the biocommunications area.

Undoubtedly, other nanostructured templates, such as the synthetic/inverse opal approach or fibrillar carbon nanotubes, will provide the basis for assembly of ordered 3D biomaterials (Innis and Wallace 2002) (Figure 44). Novel aligned carbon nanotube structures with individual filament tubes coated with bioactive (enzyme-loaded) PPy (Figure 45) have recently been produced (Gao et al 2003).

Such structures provide a high bioactive surface area with highly conducting (CNT) fibrils enabling efficient injection of electrons (polymer reduction) to control bioactivity in the manner described in the subsection Properties of polypyrroles. The integration of neurotrophin into these nanostructured materials should provide an exciting new frontier in bionic ears.

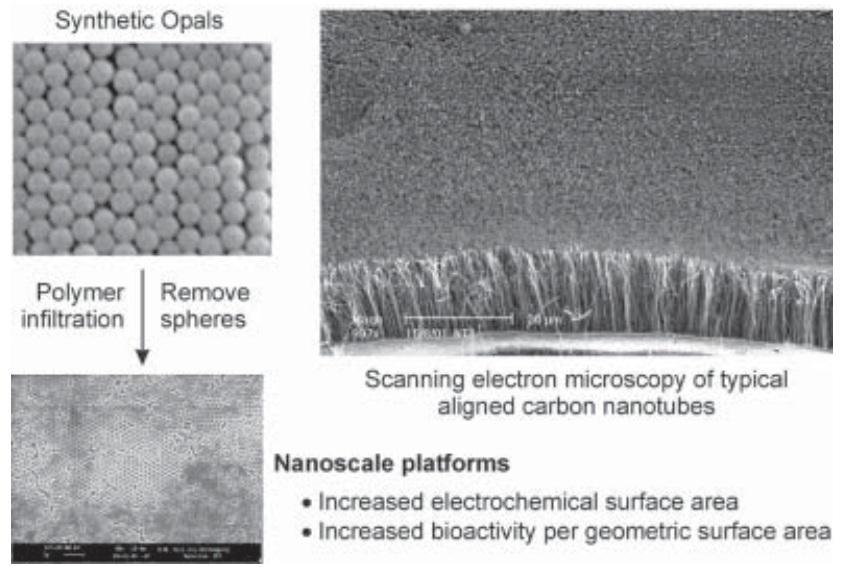

Figure 44 Assembly of nanocomponents. 


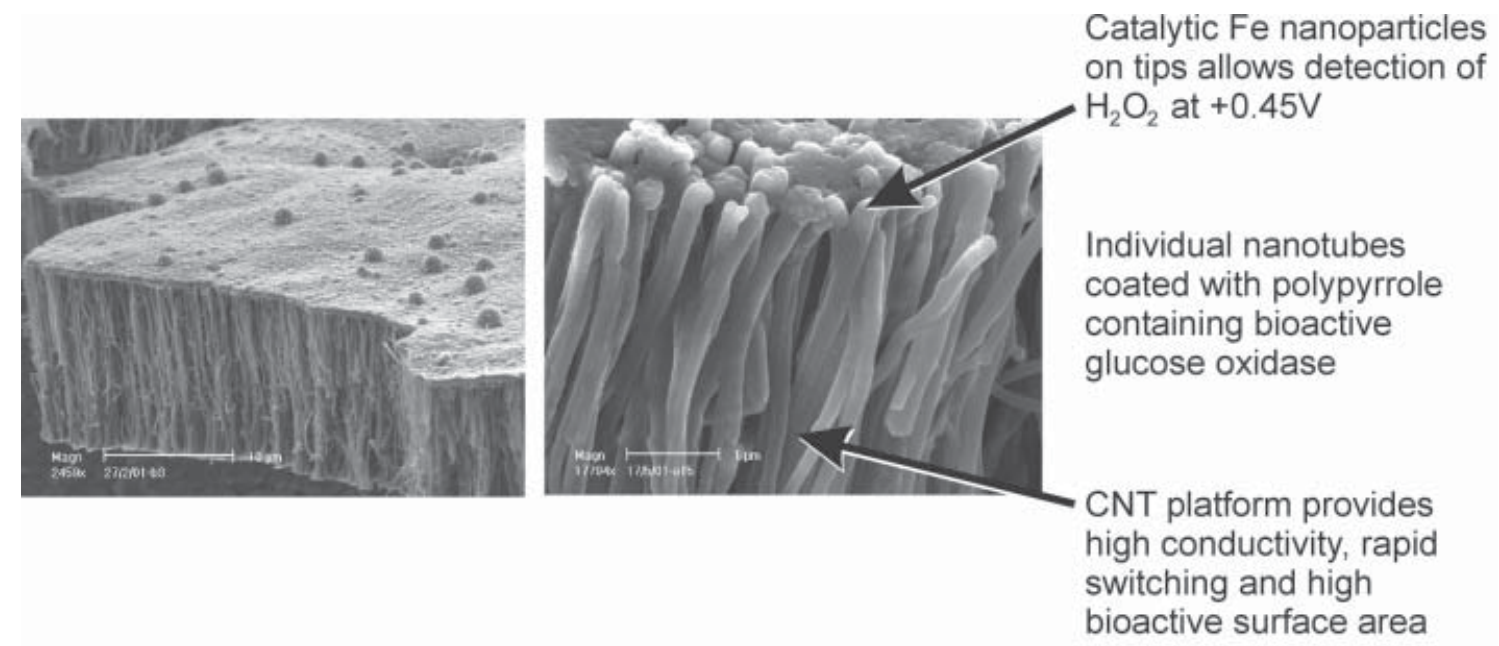

Figure 45 Novel platforms for biocommunications: polymer-coated carbon nanotubes.

\section{Biological effects and safety}

Before neurotrophins are used clinically, there is a need to determine (1) how long the molecule is stable, (2) the doseresponse curve and (3) that there are no long-term adverse effects on the body tissues. This is being confirmed through studies undertaken by the Bionic Ear Institute's Niarchos Research Unit, Victoria, Australia. This research is examining whether administration leads to apoptosis (cell death), mutagenesis (mutations) and cell proliferation. General effects on cell biochemical pathways are also being determined to ensure there are no potential adverse reactions.

The safety of ICPs is yet to be investigated in detail. However, a biodegradable ICP has recently been devised (Rivers et al 2002). The polymer consists of conducting oligomers of pyrrole and thiophene connected together via degradable ester linkages. The material was biodegradable and subject to degradation by enzymes normally found in the body. Nerve cells adhered to the new polymer structures and neurite outgrowth was observed after one day. In vivo biocompatibility was determined by subcutaneous implantation into rats. Inflammation was mild and similar to that observed with PLGA at 29 days.

Zhang et al (2001) recently investigated the biocompatibility of PPy-coated polyester fabrics for possible use as vascular prostheses. No adverse effect on haemolysis or coagulation time was observed. A low cell adhesion for endothelial cells was found for both coated textiles at 24 hours, but no cytotoxicity was detected at 72 or 168 hours. The fabrics also did not activate PMN (polymorphonuclear) cells (inflammatory cells), further confirming biocompatibility.

\section{Conclusion}

The physiological, psychophysical and speech studies with multiple-channel cochlear implants indicates the need to reproduce the fine temporal and spatial patterns of auditory nerve excitation required for high-fidelity sound and hearing in noise. The research on experimental animals using nerve growth factors indicates that the peripheral processes of the cochlear neurons can be preserved or even regenerated in sufficient numbers for this to occur. In addition, only very small quantities of neurotrophin are needed. Stimulating the peripheral processes of the cochlear nerve to reproduce the temporospatial patterns of excitation can best be achieved with electrodes close to the processes, but they will need to include inherently conducting polymers, which incorporate and release neurotrophins, to preserve the processes.

Clinical studies are yet to be carried out using the neurotrophins discussed above. However, the above review of conducting polymer-protein properties, means of protein integration and cellular communication studies suggests we are poised to develop revolutionary new nerve cell communication/recognition platforms.

It is anticipated that parallel advances in the biological aspects of inherently conducting polymers, coupled with the advances in nanotechnology as specifically related to these materials, should result in them being integral components of the next generation of bionic ears. The polymer and further studies indicate the potential of new nerve cell communication/recognition systems.

\section{Acknowledgements}

We acknowledge with gratitude the support of the Niarchos Foundation, which has been essential for the studies on 
neurotrophins. We would also like to acknowledge the $\mathrm{NIH}$ grant (NIH-N01-DC-0-2109). GGW acknowledges the continued support of the Australian Research Council (ARC) in the form of an Australian Professorial Fellowship and ARC Discovery Grant. We would like to thank Dr David Lawrence, Sue Davine and Elvis (Phil) Smugreski for help in preparing the manuscript.

\section{References}

Adeloju SB, Barisci JN, Wallace GG. 1996. Electroimmobilisation of sulfite oxidase into a polypyrrole film and its utilisation for flow amperometric detection of sulphite. Anal Chim Acta, 332:145-53.

Adeloju SB, Shaw SJ, Wallace GG. 1997. Pulsed-amperometric detection of urea in blood samples on a conducting polypyrrole urease biosensor. Anal Chim Acta, 341:155-60.

Au D, Bruce I, Irlicht L et al. 1995. Cross-fiber interspike interval probability distribution in acoustic stimulation: a computer simulation. Ann Otol Rhinol Laryngol Suppl, 166:346-9.

Austin L, Bower JJ, Kurek JB et al. 1997. Controlled release of leukaemia factor (LIF) to tissue. Growth Factors, 15:61-8.

Barisci JN, Harper G, Hodgson AJ et al. 1999. Electrochemical production of protein-containing polypyrrole colloids. Reactive Funct Polym, 39:269-75.

Barnett D, Sadik OA, John MJ et al. 1994. Pulsed amperometric detection of thaumatin using antibody-containing poly(pyrrole) electrodes. Analyst, 119:1997-2000.

Black RC, Clark GM. 1977. Electrical transmission line properties of the cat cochlea. In: Proceedings of the 28th Meeting of the Australian Physiological and Pharmacological Society. 1977; Sydney, Australia. Volume 8, p 137.

Blamey PJ, Pyman BC, Gordon M et al. 1992. Factors predicting postoperative sentence scores in postlinguistically deaf adult cochlear implant patients. Ann Otol Rhinol, 101:342-8.

Boeckl MS, Baas T, Fujita A et al. 1998. Template-assisted nano-patterning of solid surfaces. Biopolymers, 47:185-93.

Burkitt AN, Clark GM. 1999. Analysis of integrate and fire neurons: synchronization of synaptic input and spike output. Neural Comput, 11:871-901.

Busby PA, Whitford LA, Blamey PJ et al. 1994. Pitch perception for different modes of stimulation using the cochlear multiple-electrode prosthesis. J Acoust Soc Am, 95:2658-69.

Campbell TE, Hodgson AJ, Wallace GG. 1999. Incorporation of erythrocytes into polypyrrole to form the basis of a biosensor to screen for rhesus (D) blood groups and rhesus (D) antibodies. Electroanalysis, 11:215-22.

Chandrasekhar P. 1999. Conducting polymers: fundamentals and applications. Boston: Kluwer.

Chen BK, Clark GM, Jones R. 2003. Evaluation of trajectories and contact pressures for the straight nucleus cochlear implant electrode array - a two-dimensional application of finite element analysis. Med Eng Phys, 25:141-7.

Chen SJ, Wang DY, Yuan CW et al. 2000. Template synthesis of the polypyrrole tube and its bridging in vivo sciatic nerve regeneration. Mater Sci Lett, 19:2157-9.

Clark GM. 1969a. Hearing due to electrical stimulation of the auditory system. Med J Aust, 1:1346-8.

Clark GM. 1969b. Middle ear and neural mechanisms in hearing and the management of deafness [PhD thesis]. Sydney: University of Sydney.

Clark GM. 1969c. Responses of cells in the superior olivary complex of the cat to electrical stimulation of the auditory nerve. Exp Neurol, $24: 124-36$.
Clark GM. 1977. An evaluation of per-scalar cochlear electrode implantation techniques. An histopathogical study in cats. J Laryngol Otol, 91:185-99.

Clark GM. 1987. The University of Melbourne - Nucleus multi-electrode cochlear implant. In Pfaltz CR, ed. Advances in oto-rhino-laryngology. Volume 38. Basel: Karger.

Clark GM. 1996. Electrical stimulation of the auditory nerve: the coding of frequency, the perception of pitch and the development of cochlear implant speech processing strategies for profoundly deaf people. Clin Exp Pharmacol Physiol, 23:766-76.

Clark GM. 1999. Cochlear implants in the third millennium. Am J Otol, 20:4-8.

Clark GM. 2000. The cochlear implant: a search for answers. Cochlear Implants Int, 1:1-17.

Clark GM. 2001. Cochlear implants: climbing new mountains [editorial]. The Graham Fraser Memorial Lecture 2001. Cochlear Implants Int, 2:75-97.

Clark GM. 2003a. Cochlear implants in children: safety as well as speech and language. Int Pediatr Otorhinolaryngol, 67(Suppl 1):S7-20.

Clark GM. 2003b. Cochlear implants: fundamentals and applications. New York: Springer-Verlag.

Clark GM, Blamey PJ, Busby PA et al. 1987. A multiple-electrode intracochlear implant for children. Arch Otolaryngol, 113:825-8.

Clark GM, Hallworth RJ, Zdanius K. 1975. A cochlear implant electrode. J Laryngol Otol, 89:787-92.

Clark GM, Kranz HG, Minas H. 1973. Behavioral thresholds in the cat to frequency modulated sound and electrical stimulation of the auditory nerve. Exp Neurol, 41:190-200.

Clark GM, Kranz HG, Minas H et al. 1975. Histopathological findings in cochlear implants in cats. J Laryngol Otol, 89:495-504.

Clark GM, Patrick JF, Bailey QR. 1979. A cochlear implant round window electrode array. J Laryngol Otol, 93:107-9.

Clark GM, Pyman BC, Webb RL et al. 1984. Surgery for an improved multiple-channel cochlear implant. Ann Otol Rhinol Laryngol, 93: 204-7.

Clark GM, Pyman BC, Webb RL et al. 1987. Surgery for the safe insertion and reinsertion of the banded electrode array. Ann Otol Rhinol Laryngol, 96:10-12.

Clark GM, Shepherd RK, Franz BK-HG et al. 1984. Intracochlear electrode implantation. Round window membrane sealing procedures and permeability studies. Acta Otolaryngol, 410(Suppl):5-15.

Clark GM, Tong YC, Bailey QR et al. 1978. A multiple-electrode cochlear implant. J Otolaryngol Soc Aust, 4:208-12.

Clark GM, Tong YC, Martin LF. 1981. A multiple-channel cochlear implant. An evaluation using open-set CID sentences. Laryngoscope, 91:628-34.

Cochlear Corporation. 1987. Surgical procedure manual: nucleus 22 channel cochlear implant system. Issue 5. Englewood: Cochlear Corp.

Cohen LT, Saunders E, Clark GM. 2001. Psychophysics of a prototype perimodiolar cochlear implant electrode array. Hear Res, 155:63-81.

Cranswick NE, Franz BK-HG, Clark GM et al. 1987. Middle ear infection postimplantation: response of the round window membrane to streptococcus pyogenes. Ann Otol Rhinol Laryngol, 96:53-4.

Cui X, Lee VA, Raphael Y et al. 2001. Surface modification of neural recording electrodes with conducting polymer/biomolecule blends. Biomed Mater Res, 56:261-72.

Dalby MJ, Yarwood SJ, Riehle MO et al. 2002. Increasing fibroblast response to materials using nanotopography: morphological and genetic measurements of cell response to 13-nm-high polymer demixed islands. Exp Cell Res, 276:1-9.

De Giglio E, Sabbatini L, Colucci S et al. 2000. Synthesis, analytical characterization, and osteoblast adhesion properties on RGD-grafted polypyrrole coatings on titanium substrates. J Biomater Sci Polym Ed, 11:1073-83. 
De Giglio E, Sabbatini L, Zambonin PG. 1999. Development and analytical characterization of cystein-grafted polypyrrole films electrosynthesized on Pt- and Ti-substrates as precursors of bioactive interfaces. Biomater Sci Polym Ed, 10:845-58.

Dumitria S, ed. 1993. Polymeric biomaterials. New York: Marcel Dekker.

Englebienne P, Weiland M. 1996. Water-soluble conductive polymer homogeneous immunoassay (SOPHIA). A novel immunoassay capable of automation. J Immunol Methods, 191:159-70.

Fitzgerald JV, Burkitt AN, Clark GM et al. 2001. Delay analysis in the auditory brainstem of the rat: comparison with click latency. Hear Res, 159:85-100.

Fowler EP. 1968. The second one hundred years. Musings and dreams of things to come. In: History of the American Otological Society, Inc. 1868-1968. St Louis: American Otological Society. p 125-9.

Franz BK-HG, Clark GM, Bloom D. 1984. Permeability of the implanted round window membrane in the cat-an investigation using horseradish peroxidase. Acta Otolaryngol, 410(Suppl):17-23.

Gao M, Dai L, Wallace GG. 2003. Glucose sensors based on glucoseoxidase-containing polypyrrole/aligned carbon nanotube coaxial nanowire electrodes. Synthetic Met, 137:1393-4.

Garner B, Georgevich A, Hodgson AJ et al. 1999. Polypyrrole-heparin composites as stimulus-responsive substrates for endothelial cell growth. J Biomed Mater Res, 44:121-9.

Garner B, Hodgson AJ, Wallace GG et al. 1999. Human endothelial cell attachment to and growth on polypyrrole-heparin is vitronectin dependent. J Mater Sci Mater Med, 10:19-27.

Gillespie LN, Clark GM, Bartlett PF et al. 2001. LIF is more potent than $\mathrm{BDNF}$ in promoting neurite outgrowth of mammalian auditory neurons in vitro. Neuroreport, 12:275-9.

Gillespie LN, Clark GM, Bartlett PF et al. 2003. BDNF-induced survival of auditory neurons in vivo: cessation of treatment leads to accelerated loss of survival effects. J Neurosci Res, 71:785-90.

Goodhill V. 1979. Progress in otology. Ann Otol Rhinol Laryngol, 88: $658-63$.

Hodgson AJ, Gilmore K, Small C et al. 1994. Reactive supramolecular assemblies of mucopolysaccharide, polypyrrole and protein as controllable biocomposites for a new generation of 'intelligent biomaterials'. Supramol Sci, 1:77-83.

Hodgson AJ, John MJ, Campbell T et al. 1996. Integration of biocomponents with synthetic structures - use of conducting polymer polyelectrolyte composites. Proc SPIE, 2716:164-76.

Illum L, Davis S. 1987. Polymers in controlled drug delivery. Bristol: IOP Publ.

Innis PC, Wallace GG. 2002. Inherently conducting polymer nanostructures. J Nanosci Nanotechnol, 2:441-51.

Johnson DH. 1980. The relationship between spike rate and synchrony in responses of auditory-nerve fibres to single tones. $J$ Acoust Soc Am, 68:1115-22.

Kane-Maguire LAP, Wallace GG. 2002. Manipulating and monitoring biomolecular interactions with conducting electroactive polymers. $A d v$ Mater, 14:953-60.

Khan GF, Wernet W. 1997. Adsorption of proteins on electro-conductive polymer films. Thin Solid Films, 300:265-71.

Kotwal A, Schmidt CE. 2001. Electrical stimulation alters protein adsorption and nerve cell interactions with electrically conducting biomaterials. Biomaterials, 22:1055-64.

Lawrence M. 1964. Direct stimulation of auditory nerve fibers. Arch Otolaryngol, 80:367-8.

Malmsten M, ed. 2003. Biopolymers at interfaces. New York: Marcel Dekker.

Marzella PL, Clark GM. 1999. Growth factors, auditory neurones and cochlear implants: a review. Acta Otolaryngol, 119:407-12.

Marzella PL, Clark GM, Shepherd RK et al. 1997. The interactions between the cytokine LIF and the neurotrophins on spiral ganglion cells. In Clark GM, ed. Cochlear implants. Bologna: Monduzzi Editore. p 131-5.
Merzenich MM. 1975. Studies on electrical stimulation of the auditory nerve in animals and man: cochlear implants. In Tower DB, ed. The nervous system. Volume 3: Human communication and its disorders. New York: Raven Pr. p 537-48.

Minett AI, Barisci JN, Wallace GG. 2002. Immobilisation of anti-Listeria in a polypyrrole film. Reactive Funct Polym, 53:217-27.

Minett AI, Barisci JN, Wallace GG. 2003. Coupling conducting polymers and mediated electrochemical responses for the detection of Listeria. Anal Chim Acta, 475:37-45.

Misoska V, Price WE, Ralph SF et al. 2001. Synthesis, characterisation and ion transport studies on polypyrrole/deoxyribonucleic acid conducting polymer membranes. Synthetic Met, 123:279-86.

Nadol JB, Young Y-S, Glynn RB. 1989. Survival of spiral ganglion cells in profound sensorineural hearing loss: implications for cochlear implantation. Ann Otol Rhinol Laryngol, 98:411-16.

Neely ST, Kim DO. 1986. A model for active elements in cochlear biomechanics. J Acoust Soc Am, 79:1472-80.

Paolini AG, FitzGerald JV, Burkitt AN et al. 2001. Temporal processing from the auditory nerve to the medial nucleus of the trapezoid body in the rat. Hear Res, 159:101-16.

Petit MA, Zante D, Colin C et al. 2001. Evaluation of a polypyrrole film containing anti-isoproturon antibodies for the detection of isoproturon. Electroanalysis, 13:856-9.

Rivers TJ, Hudson TW, Schmidt CE. 2002. Synthesis of a novel, biodegradable electrically conducting polymer for biomedical applications. Adv Funct Mater, 12:33-7.

Sadik OA, Wallace GG. 1993. Pulsed amperometric detection of proteins using antibody containing conducting polymers. Anal Chim Acta, 279:209-12.

Schmidt CE, Shastri VR, Vacanti JP et al. 1997. Stimulation of neurite outgrowth using an electrically conducting polymer. Proc Natl Acad Sci USA, 94:8948-53.

Shastri VR, Schmidt CE, Kim TH et al. 1996. Polypyrrole - a potential candidate for stimulated nerve regeneration. Mater Res Soc Symp Proc, 414:113-18.

Shepherd R, Epp S, Crook J et al. 2002. Protective effects of patterned electrical stimulation on the deafened auditory system. Ninth quarterly progress report NIH-N01-DC-0-2109, October 1-December 30. Melbourne: Department of Otolaryngology, University of Melbourne.

Shepherd RK, Clark GM, Black RC. 1983. Chronic electrical stimulation of the auditory nerve in cats. Physiological and histopathological results. Acta Otolaryngol, 399(Suppl):19-31.

Shepherd RK, Franz BK-HG, Clark GM. 1990. The biocompatibility and safety of cochlear prostheses. In Clark GM, Tong YC, Patrick JF, eds. Cochlear prostheses. London: Churchill Livingstone. p 69-98.

Shirakawa H, Louis EJ, MacDiarmid AG et al. 1977. Synthesis of electrically conducting organic polymers: halogen derivatives of polyacetylene, $(\mathrm{CH})_{\mathrm{x}}$. J Chem Soc Chem Commun, p 578-80.

Simmons FB. 1966. Electrical stimulation of the auditory nerve in man. Arch Otolaryngol, 84:2-54.

Skotheim TA, Elsenbaumer RL, Reynolds JR, eds. 1998. Handbook of conducting polymers. New York: Marcel Dekker.

Smith AB, Knowles CJ. 1990. Potential role of a conducting polymer in biochemistry: protein-binding properties. Biotechnol Appl Biochem, 12:661-9.

Tong YC, Blamey PJ, Dowell RC et al. 1983. Psychophysical studies evaluating the feasibility of a speech processing strategy for a multiplechannel cochlear implant. $J$ Acoust Soc Am, 74:73-80.

Tong YC, Clark GM, Blamey PJ et al. 1982. Psychophysical studies for two multiple-channel cochlear implant patients. J Acoust Soc Am, $71: 153-60$.

Tong YC, Clark GM, Seligman PM et al. 1980. Speech processing for a multiple-electrode cochlear implant hearing prosthesis. J Acoust Soc Am, 68:1897-9.

Wallace GG, Spinks GM, Kane-Maguire LAP et al. 2003. Conductive electroactive polymers. New York: CRC Pr. 
Wilson BS, Lawson DT, Zerbi M et al. 1992. Speech processors for auditory prostheses. Twelfth quarterly progress report, April 1992. NIH contract nr 1-DC-2-2401. Durham: Research Triangle Institute.

Wong JY, Langer R, Ingber DE. 1994. Electrically conducting polymers can noninvasively control the shape and growth of mammalian cells. Proc Natl Acad Sci USA, 91:3201-4.

Yon-Hin BFY, Smolander M, Crompton T et al. 1993. Covalent electropolymerization of glucose oxidase in polypyrrole. Evaluation of methods of pyrrole attachment to glucose oxidase on the performance of electropolymerized glucose sensors. Anal Chem, 65:2067-71.
Zhang Z, Roy R, Dugré FJ et al. 2001. In vitro biocompatibility study of electrically conductive polpyrrole-coated polyester fabrics. Biomed Mater Res, 57:63-71.

Zhou D, Too CO, Wallace GG. 1999. Synthesis and characterization of polypyrrole/heparin composites. Reactive Funct Polym, 39:19-26.

Zhou D, Wallace GG, Too CO. 1997. Dynamic polymeric membrane structures for separation of proteins. J Intell Mater Syst Struct, 8: $1052-8$.

Zimmerli W, Waldvogel FA, Vaudaux P et al. 1982. Pathogenesis of foreign body infection: description and characteristics of an animal model. J Infect Dis, 146:487-97. 


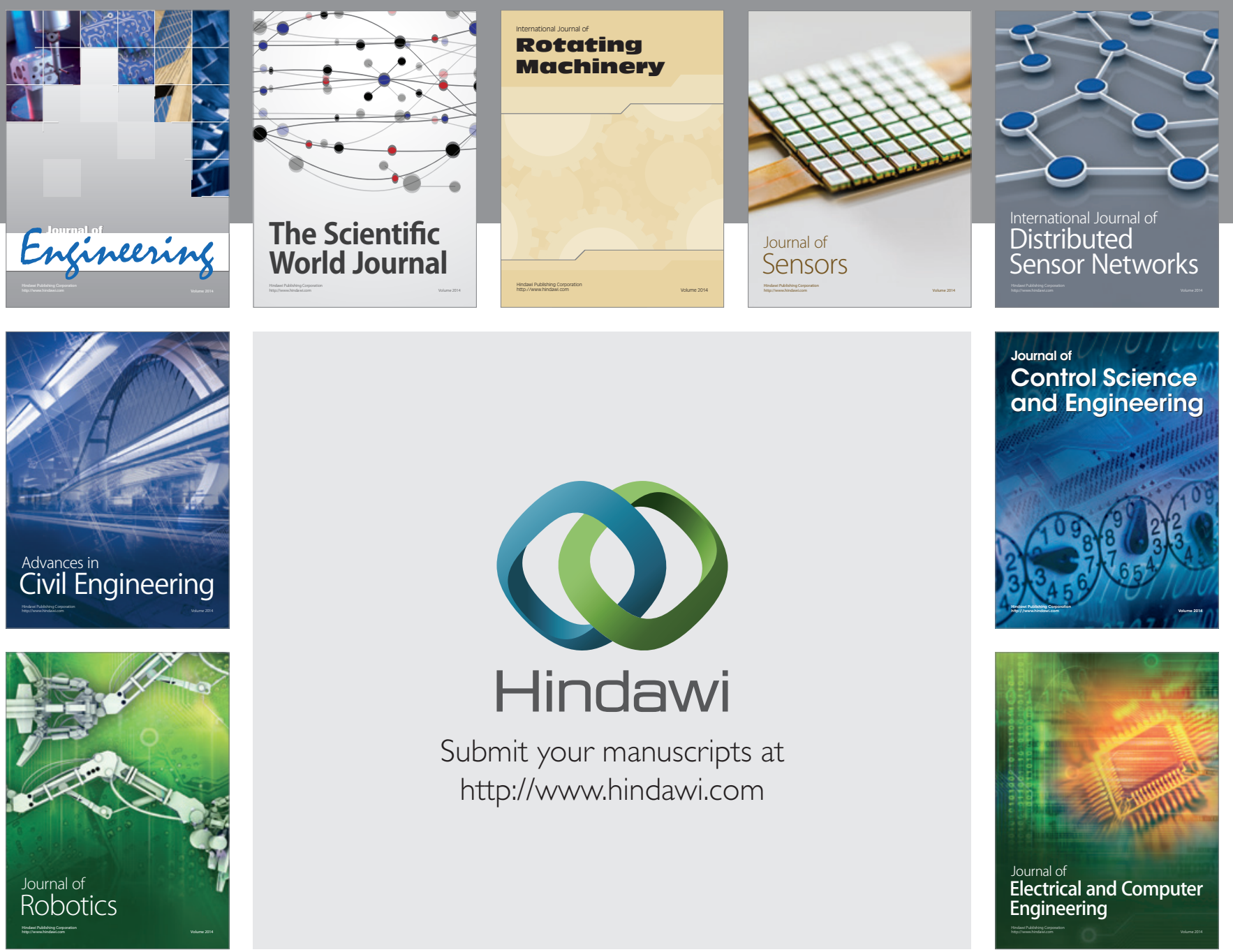

Submit your manuscripts at

http://www.hindawi.com
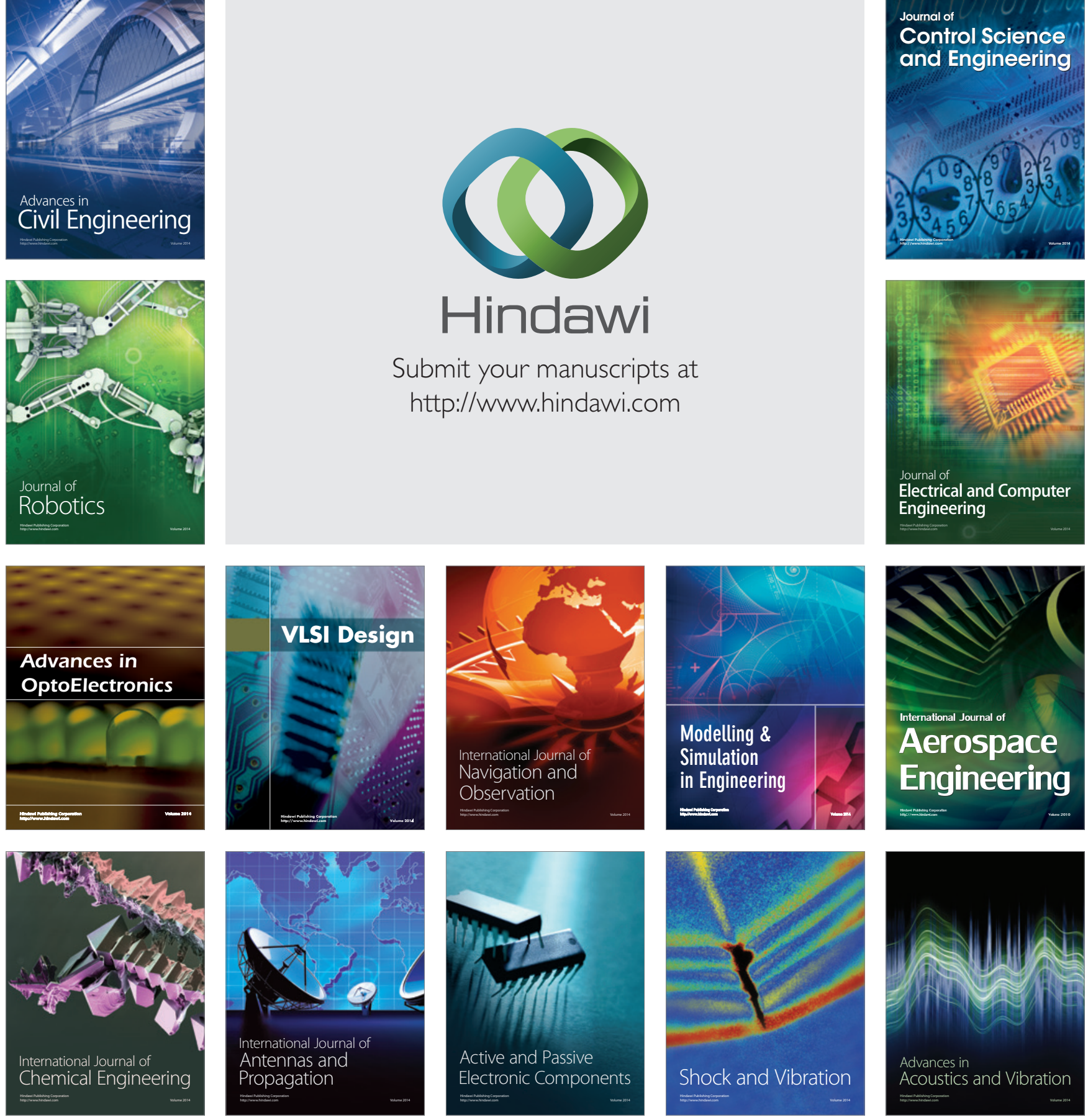